\title{
Full-Year Evaluation of Nonmeteorological Echo Removal with Dual-Polarization Fuzzy Logic for Two C-Band Radars in a Temperate Climate ${ }^{\mathscr{O}}$
}

\author{
AART OVEREEM \\ $R \& D$ Observations and Data Technology, Royal Netherlands Meteorological Institute, De Bilt, and Hydrology and \\ Quantitative Water Management Group, Wageningen University and Research, Wageningen, Netherlands \\ REMKO UIJLENHOET \\ Hydrology and Quantitative Water Management Group, Wageningen University and Research, Wageningen, Netherlands \\ HIDDE LEIJNSE \\ $R \& D$ Observations and Data Technology, Royal Netherlands Meteorological Institute, De Bilt, Netherlands
}

(Manuscript received 2 September 2019, in final form 26 June 2020)

\begin{abstract}
The Royal Netherlands Meteorological Institute (KNMI) operates two dual-polarization C-band weather radars in simultaneous transmission and reception (STAR; i.e., horizontally and vertically polarized pulses are transmitted simultaneously) mode, providing 2D radar rainfall products. Despite the application of Doppler and speckle filtering, remaining nonmeteorological echoes (especially sea clutter) mainly due to anomalous propagation still pose a problem. This calls for additional filtering algorithms, which can be realized by means of polarimetry. Here we explore the effectiveness of the open-source wradlib fuzzy echo classification and clutter identification based on polarimetric moments. Based on our study, this has recently been extended with the depolarization ratio and clutter phase alignment as new decision variables. Optimal values for weights of the different membership functions and threshold are determined employing a 4-h calibration dataset from one radar. The method is applied to a full year of volumetric data from the two radars in the Dutch temperate climate. The verification focuses on the presence of remaining nonmeteorological echoes by mapping the number of exceedances of radar reflectivity factors for given thresholds. Moreover, accumulated rainfall maps are obtained to detect unrealistically large rainfall depths. The results are compared to those for which no further filtering has been applied. Verification against rain gauge data reveals that only a little precipitation is removed. Because the fuzzy logic algorithm removes many nonmeteorological echoes, the practice to composite data from both radars in logarithmic space to hide these echoes is abandoned and replaced by linearly averaging reflectivities.
\end{abstract}

\section{Introduction}

Quantitative precipitation estimation (QPE) from ground-based weather radars can suffer from overestimates due to nonmeteorological echoes. This can hinder reliable nowcasting, can mislead the general public and weather forecasters, and negatively affect hydrological

Supplemental information related to this paper is available at the Journals Online website: https://doi.org/10.1175/JTECH-D-190149.s1.

Corresponding author: Aart Overeem, overeem@knmi.nl applications. Operational 2D radar rainfall products for the Netherlands are extensively used for, e.g., nowcasting, water management, and climatological purposes. For example, the Royal Netherlands Meteorological Institute (KNMI) warning system for water authorities uses the precipitation history, combined with nowcasting of precipitation from weather radar and a numerical weather prediction model to forecast rainfall (Kok et al. 2011).

Publisher's Note: This article was revised on 31 August 2020 to include an acknowledgment in the Acknowledgments section that was missing when originally published. 
Taking into account the local discharge and storage capacity, automatic warnings are issued if preselected thresholds of rainfall depths are exceeded with a certain probability. The occurrence of residual ground clutter in radar data has led to several automatic warnings, hence negatively affecting operational water management.

Nonmeteorological echoes are called clutter. For weather radars these can be caused by, e.g., chaff, insects, and birds. Clutter is often caused by anomalous propagation, i.e., a larger-than-normal fraction of the beam which will reach Earth's surface due to superrefraction. This occurs when the temperature decrease with height is smaller than normal (or even increases). This can also arise in case of a larger-than-normal decrease of moisture with height. These conditions may, e.g., occur for inversions in high pressure areas. Hence, Earth's surface can give rise to a large backscatter. This may also occur when no superrefraction takes place due to nearby obstacles including buildings and mountains (Fabry 2015). Although these artifacts can contain useful finescale weather signatures for assessing the current weather situation, they also hamper reliable QPE.

Many studies have considered a variety of techniques to remove nonmeteorological echoes. Doppler filtering is commonly applied, intended to remove the part of the power caused by clutter, but it is especially difficult to remove nonstationary clutter (e.g., waves, ships, wind farms). Thus, often additional methods are needed to further reduce nonmeteorological echoes. Many studies employ fuzzy logic algorithms involving single-polarization (single-pol) and/or dual-polarization (dual-pol) decision variables (Berenguer et al. 2006; Gourley et al. 2007; Vulpiani et al. 2012; Crisologo et al. 2014; Krause 2016), where a range bin classified as clutter is entirely discarded, although its value may be replaced by an interpolated value from neighboring range bins. This is often accompanied by pre or postprocessing, where for the latter the original classification made by the fuzzy logic algorithm can be overruled (Gourley et al. 2007). Also, statistical postprocessing is applied, e.g., by creating clutter maps based on unrealistically large accumulations or numbers of exceedances or by removing data with high values of the spatial variability in the radar reflectivity factor, called texture. More information is provided by Fabry (2015), Zhang (2017), and Rauber and Nesbitt (2018). Numerous other studies use hydrometeor classification algorithms, which may also include clutter detection (e.g., Vivekanandan et al. 1999; Park et al. 2009; Bechini and Chandrasekar 2015). Michelson and Sunhede (2004) and Magaldi et al. (2009) remove clutter by developing (precipitating cloud) masks constructed from geostationary satellite data and 2-m air temperatures from a numerical weather prediction model.
Dual-pol radars offer additional possibilities to detect nonmeteorological echoes, because of the often irregular surface of the scatterers in contrast to most meteorological echoes. Hydrometeors are usually near spherical, except for, e.g., large rain droplets and tiny ice crystals, and have low shape diversity, which distinguishes them from nonmeteorological echoes. Differences in amplitude and phase between horizontally and vertically polarized backscattered signals are therefore generally larger for nonmeteorological echoes. A useful echo classification is possible by using (the texture of) the polarimetric variables differential reflectivity, two-way differential propagation phase, and copolar correlation coefficient (Hubbert et al. 2009b; Fabry 2015).

The goal of this study is to remove as many nonmeteorological echoes as possible while removing as few precipitation echoes as possible from a full-year dataset from two C-band radars in a temperate climate. This study forms the basis for the extension of the wradlib fuzzy echo classification with clutter phase alignment (CPA; Hubbert et al. 2009a) and depolarization ratio (DR; Ryzhkov et al. 2017). Hubbert et al. (2009b) already successfully use CPA in a fuzzy logic algorithm, whereas Kilambi et al. (2018), who employ DR to successfully classify nonmeteorological echoes, suggest the inclusion of DR as an input to future identification algorithms. This has, to the best of our knowledge, not been attempted before. The main contribution of this study is available through the open-source Python library for weather radar data processing wradlib (Heistermann et al. 2013). It is an extension to the original fuzzy logic algorithm, which was applied to C-band radar data from Mediterranean and mountainous climates in Italy (Vulpiani et al. 2012) and from a tropical climate in the Philippines (Crisologo et al. 2014). This study aims to test the fuzzy logic algorithm for a temperate climate. A method for determining optimal weights and threshold of the fuzzy logic algorithm is presented and applied to a 4-h calibration dataset. Occasionally, an Integrated Multisatellite Retrievals for Global Precipitation Measurement (IMERG) product is employed to assess whether it is raining or not over ungauged areas.

Results follow a twin track by systematically investigating 1) the presence of remaining nonmeteorological echoes by mapping the number of exceedances of radar reflectivity factors for given thresholds and 2) the consequences for QPE by means of annual rainfall accumulations, verification of hourly and daily rainfall against gauges, and case studies. The latter encompasses not only the detection of unrealistically large rainfall depths, but also provides a means to quantify unwanted precipitation removal. This is one of the few studies 

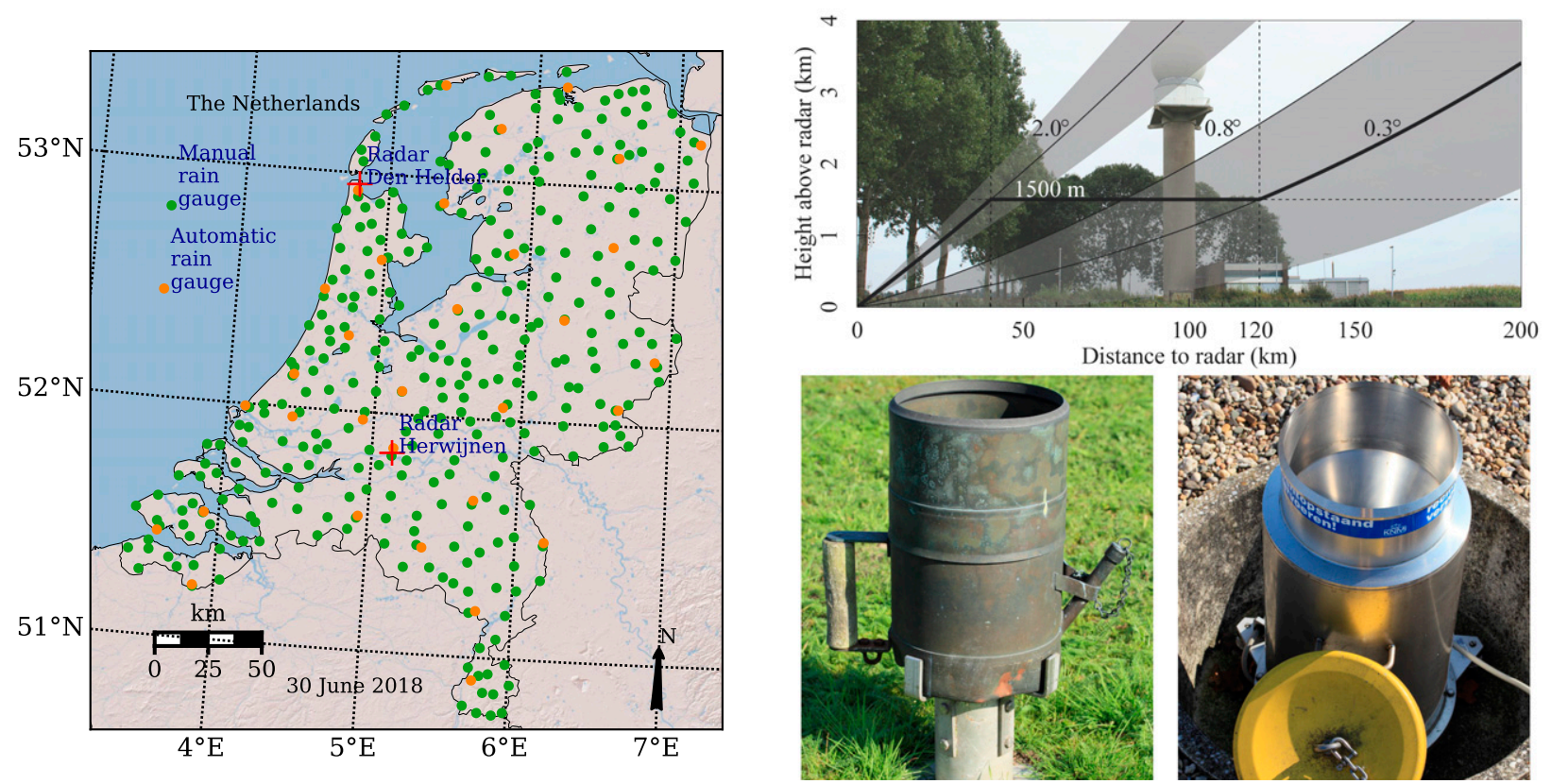

FIG. 1. (left) Map of the Netherlands with locations of KNMI's weather radars, and automatic and manual rain gauges. (top right) Volume coverage pattern showing the employed elevation scans and their height above the radar as a function of distance from the radar with the radar tower in Herwijnen in the background. The thick black line denotes the pseudo-CAPPI height, and the grayshaded areas indicate the $1^{\circ}$ beam for the lowest and highest employed elevation scan. (bottom right) Photos of the manual and automatic rain gauge.

where nonmeteorological echo removal is applied to a large dataset (i.e., a full year of data from two radars) instead of merely a few or tens of case studies (or events), or a few months (e.g., Berenguer et al. 2006; Crisologo et al. 2014).

Section 2 gives a description of the employed radar, rain gauge, and satellite data. In section 3 the nonmeteorological echo classification and removal, the derivation of pseudo-constant-altitude plan position indicators (pseudo-CAPPI) images, the compositing of those images and the rainfall retrieval are explained. Section 4 evaluates the performance of the fuzzy logic algorithm, and section 5 highlights a number of discussion points. This paper ends with conclusions and some recommendations in section 6 .

\section{Data}

\section{a. Radars}

KNMI operates two Gematronik METEOR 735CDP10 magnetron based C-band dual-pol Doppler weather radars, located in the Netherlands in Den Helder $\left(52.953^{\circ} \mathrm{N}\right.$, $4.790^{\circ} \mathrm{E}, 51.0 \mathrm{~m} \mathrm{MSL}, \mathrm{WMO}$ code 6234$)$ and Herwijnen $\left(51.837^{\circ} \mathrm{N}, 5.138^{\circ} \mathrm{E}, 27.7 \mathrm{~m}\right.$ MSL, WMO code 6356$)$. They work in simultaneous transmission and reception (STAR; i.e., horizontally and vertically polarized pulses are transmitted simultaneously) mode, have an antenna diameter of $4.3 \mathrm{~m}$, a wavelength of $5.326 \mathrm{~cm}(5.6 \mathrm{GHz})$, an antenna gain of $45 \mathrm{~dB}$, a transmit peak power of $500 \mathrm{~kW}$ (i.e., $250 \mathrm{~kW}$ per polarization), and a $3-\mathrm{dB}$ beamwidth of $0.905^{\circ}$. Solar monitoring is employed to, e.g., detect deviations in the pointing of the antenna as small as $0.05^{\circ}$ (Beekhuis and Mathijssen 2018), and a speckle filter is applied to remove isolated range bins with valid data surrounded by range bins with no data (Leijnse et al. 2016). Beekhuis and Mathijssen (2018) provide more information on these radars, such as the hardware calibration. The starting point for this study is the 16-bit volumetric data from both radars from the period 0800 UTC 31 July 2017-0800 UTC 31 July 2018, with an availability of $98.8 \%$ and $99.2 \%$ for the radar in Den Helder and Herwijnen, respectively. Note that missing radar data are mainly caused by IT problems and planned maintenance, but rarely by malfunctioning radars. Every $5 \mathrm{~min}$, the radars perform 16 azimuthal scans of $360^{\circ}$ around a vertical axis. Data from elevation scans $5\left(2.0^{\circ}\right), 6\left(0.8^{\circ}\right)$, and $7\left(0.3^{\circ}\right)$ were employed, since these are used for deriving operational radar precipitation products. Figure 1 displays the radar locations, as well as the volume coverage pattern for these elevation scans. Table 1 lists characteristics of the utilized elevation scans. 
TABLE 1. Technical characteristics of the employed radar elevation scans.

\begin{tabular}{lccc}
\hline \hline \multicolumn{1}{c}{ Characteristic } & Scan 5 & Scan 6 & Scan 7 \\
\hline Elevation angle $\left({ }^{\circ}\right)$ & 2.0 & 0.8 & 0.3 \\
Pulse repetition & 600 and 800 & 600 and 800 & 450 \\
$\quad$ frequency $(\mathrm{Hz})$ & 1.49 & 1.49 & 2.66 \\
Pulse duration $(\mu \mathrm{s})$ & 24 & 24 & 12 \\
Antenna rotation speed $\left({ }^{\circ} \mathrm{s}^{-1}\right)$ & 360 & 360 & 360 \\
No. of azimuths & 838 & 838 & 802 \\
No. of range bins & 223.5 & 223.5 & 399.0 \\
Range bin width $(\mathrm{m})$ & $\sim 29$ & $\sim 29$ & $\sim 38$ \\
No. of pulses per azimuth bin & & & \\
\hline
\end{tabular}

\section{b. Rain gauges}

KNMI operates two rain gauge networks. Hourly (each clock hour) and daily (0800-0800 UTC) rainfall depths were obtained from the automatic network of 32 gauges (density of $\sim 1$ gauge per $1000 \mathrm{~km}^{2}$ ) and the manual network of 322 gauges (density of $\sim 1$ gauge per $100 \mathrm{~km}^{2}$ ), respectively (Fig. 1). These are employed for validation of hourly and daily radar rainfall depths. In addition, the daily rainfall depths from manual gauges were accumulated to annual rainfall depths for the validation of annual radar rainfall depths. The automatic gauges are electronic ones that measure the precipitation depth using the displacement of a float placed in a reservoir, whereas the manual rain gauges are read by volunteers (KNMI 2000).

\section{c. Satellites: IMERG}

The IMERG V05B Final Run precipitationCal product was obtained from NASA (Hou et al. 2014; SkofronickJackson et al. 2018). This Global Precipitation Measurement (GPM) level-3 product provides gridded rainfall information every $30 \mathrm{~min}$ at a spatial resolution of $0.1^{\circ} \times 0.1^{\circ}$ $\left(\sim 7 \times 11 \mathrm{~km}^{2}\right.$ at the latitudes of the Netherlands). IMERG was only used to verify whether it was raining or not for regions where no rain gauge data were available for five time intervals.

\section{Methods}

The flowchart in Fig. 2 provides an overview of the radar data processing chain. The starting point is the volumetric radar data from the two KNMI radars. First, the fuzzy logic echo classification and clutter identification based on polarimetric moments from the open-source Python library for weather radar data processing wradlib is applied (Heistermann et al. 2013). Next, $1500-\mathrm{m}$ pseudo-CAPPI images of radar reflectivity factors are obtained for each radar, which are subsequently merged into one composite using either linear or logarithmic averaging. Finally, 5-min rainfall intensities are retrieved from the horizontal reflectivity composites using the Marshall-Palmer $Z_{\mathrm{h}}-R$ relation $\left(Z_{\mathrm{h}}=200 R^{1.6}\right)$, which are accumulated to hourly, daily, and annual rainfall depths.

\section{a. Nonmeteorological echo classification and removal}

\section{1) FuZZY LOGIC ALGORITHM}

The function "clutter.classify_echo_fuzzy” from wradlib, version 1.4.2 (Mühlbauer and Heistermann 2019), is employed to classify and remove nonmeteorological echoes from volumetric radar data by utilizing a number of decision variables. This fuzzy logic echo classification is based on Vulpiani et al. (2012) and Crisologo et al. (2014), where the latter added $\rho_{\mathrm{HV}}$ as a decision variable. Wradlib has been extended as of version 1.4.0 with the decision variables CPA and DR (function "dp.depolarization"). The other decision variables are texture of the differential reflectivity $Z_{\mathrm{DR}}$ (TxZdr), texture of the copolar correlation coefficient $\rho_{\mathrm{HV}}$ (TxRho), texture of the two-way differential propagation phase $\Phi_{\mathrm{DP}}(\mathrm{TxPhi})$, and the copolar correlation coefficient $\rho_{\mathrm{HV}}$ (Rho). The static clutter map (CMAP) and the Doppler velocity $(V)$ were not considered. Clutter maps may vary depending on weather conditions (Zhang 2017) and a static clutter map, based on long radar records, only represents the average influence of clutter. Hence, it will often be less representative for an individual time interval. Because of this, the classification is entirely based on the radar data from the considered time interval. Since Doppler filtering has already been applied at the radar's signal processor (Leijnse et al. 2016), the main objective is to remove nonstationary clutter. Hence, using radial velocity seems unnecessary and could even interfere with this objective, which is why it was discarded.

CPA is a measure of the pulse-to-pulse phase variability of the signal for a range bin, and shows less fluctuation in case of ground echoes (Hubbert et al. 2009a,b):

$$
\mathrm{CPA}=\left|\sum_{i=1}^{N} x_{i}\right| /\left(\sum_{i=1}^{N}\left|x_{i}\right|\right),
$$

where $x_{i}$ is an individual time series member. DR is a $2 \mathrm{D}$ combination of $Z_{\mathrm{DR}}$ and $\rho_{\mathrm{HV}}$ and a proxy quantity to the circular depolarization ratio. DR can be computed as follows (Ryzhkov et al. 2017; Kilambi et al. 2018):

$$
\mathrm{DR}=10 \log _{10}\left[\frac{Z_{\mathrm{dr}}+1-2\left(Z_{\mathrm{dr}}\right)^{0.5} \rho_{\mathrm{HV}}}{Z_{\mathrm{dr}}+1+2\left(Z_{\mathrm{dr}}\right)^{0.5} \rho_{\mathrm{HV}}}\right],
$$

where $Z_{\mathrm{dr}}$ is in linear scale. High depolarization ratios point to nonmeteorological echoes, whereas meteorological echoes generally have $Z_{\mathrm{DR}}$ values relatively close 


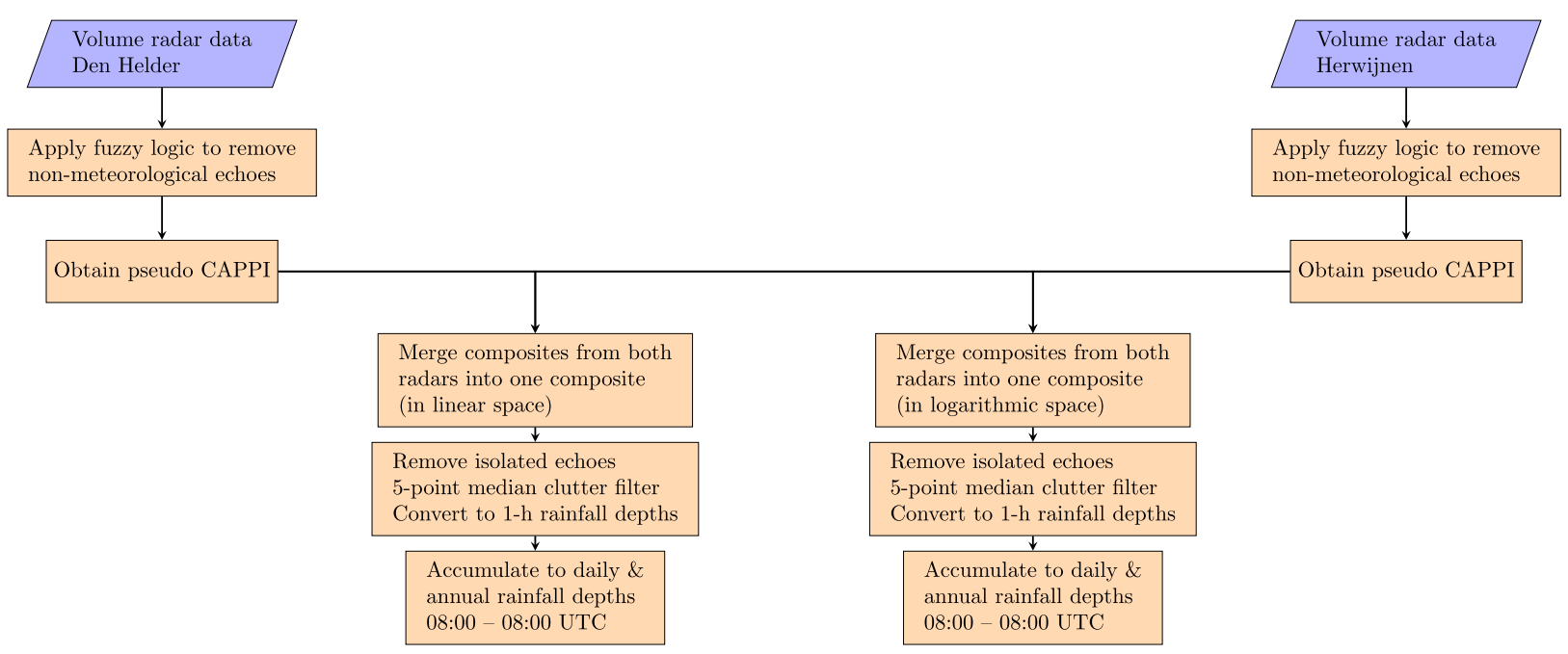

FIG. 2. Flowchart of radar data processing.

to $0 \mathrm{~dB}\left(-1<Z_{\mathrm{DR}}<3 \mathrm{~dB}\right)$ and have low shape diversity (high $\rho_{\mathrm{HV}}$ ); i.e., they have low polarization (Kilambi et al. 2018). Note that all employed decision variables can only be available for dual-pol radars, except for CPA. The texture is computed over a $3 \times 3$ neighborhood, i.e., over 3 bins in azimuth and 3 bins in range, using function "dp.texture". This spatial variability is computed as the root-mean-square difference of the 8 surrounding range bins with respect to the center range bin, to which the fuzzy logic algorithm is applied (Gourley et al. 2007).

The rationale for the use of textures for nonmeteorological echo removal is that nonmeteorological echoes have very limited spatial extents, and hence textures will be large. For many nonmeteorological echoes encountered in the Netherlands (very limited topography), spatial extents

$$
d\left(X_{j}\right)=\left\{\begin{array}{l}
0 \\
\left(X_{j}-X_{1, j}\right) /\left(X_{2, j}-X_{1, j}\right) \\
\left(X_{4, j}-X_{j}\right) /\left(X_{4, j}-X_{3, j}\right) \\
1
\end{array}\right.
$$

where $X_{i, j}$ is the $i$ th vertex of the trapezoid relative to the $j$ th decision variable, and $X_{j}$ is the value of the $j$ th decision variable. Subsequently, the degree of membership to the nonmeteorological target class is subtracted from 1 to obtain the degree of membership to the meteorological target class. This is multiplied by the weight of the decision variable. Next, the contributions from each decision variable are summed and divided by the sum of the weights of all decision variables. The echo is assumed to be nonmeteorological in will typically be smaller than the size of the range bins. Also note that radar sample volume sizes are dependent on the range (in the azimuth dimension), so textures may also be affected by that. Hence, employing a single set of membership functions (see below) for different scans and ranges is justified.

For each decision variable and range bin, the degree of membership to the nonmeteorological target class is computed by using trapezoidal transformation functions (function "util.trapezoid"). For instance, the degree of membership $d\left(X_{j}\right)$ is 0 for CPA $\leq 0.6$, thus considered as meteorological. Then it increases linearly to 1 for $\mathrm{CPA}=0.9$. Values of $\mathrm{CPA} \geq 0.9$ are considered as nonmeteorological. The degree of membership is computed from membership values $X$ (Vulpiani et al. 2012):

$$
\begin{array}{ll}
\text { if } & X_{j}<X_{1, j} \quad \text { or } \quad X_{j}>X_{4, j} \\
\text { if } & X_{1, j}<X_{j}<X_{2, j} \\
\text { if } & X_{3, j}<X_{j}<X_{4, j} \\
\text { if } & X_{2, j}<X_{j}<X_{3, j}
\end{array},
$$

case this weighted average of the degree of membership to the meteorological target class is lower than a threshold value ( 0.6 in this study). In this case the horizontally polarized radar reflectivity factor $\left(Z_{\mathrm{h}}\right)$ of the range bin is set to a not available (NA) value. Otherwise the echo is classified as meteorological. If a decision variable is NA for a given range bin, its weight becomes 0 , implying that only other decision variables are used for the classification, and effectively get a larger relative weight. 
TABLE 2. Parameters of the membership functions for the employed decision variables of the fuzzy logic echo classification procedure and their weights. A threshold of 0.6 is applied. The clutter map (CMAP) and radial velocity $(V)$ were not employed; i.e., their weight is 0 .

\begin{tabular}{lccccc}
\hline \hline \multicolumn{1}{c}{$X_{j}$} & Description & Weight & $X_{1, j}$ & $X_{2, j}$ & $X_{3, j}$ \\
\hline TxZdr & Texture of $Z_{\mathrm{DR}}$ & 0.20 & 0.7 & 1.0 & 9999 \\
TxRho & Texture of $\rho_{\mathrm{HV}}$ & 0.25 & 0.1 & 0.15 & 9999 \\
TxPhi & Texture of $\Phi_{\mathrm{DP}}$ & 0 & 15 & 20 & 10000 \\
Rho & $\rho_{\mathrm{HV}}$ & 0.15 & -9999 & -9999 & 9999 \\
DR & DR & 0.20 & -20 & -12 & 0.8 \\
CPA & CPA & 0.20 & 0.6 & 0.9 & 9999 \\
\hline
\end{tabular}

The wradlib default membership values are used (Table 2) except for "Rho," for which much lower values are employed: $0.8-0.85$ instead of $0.95-0.98$ (wradlib's), because values below 0.8 are generally associated with nonmeteorological scatterers Kumjian (2013). Crisologo et al. (2014) use 0.9-0.95 in a tropical climate, whereas the values used for the United States by Krause (2016), 0.75-0.9, encompass the ones employed in this study. The membership values for CPA are obtained from Hubbert et al. (2009b). Kilambi et al. (2018) report that DR exceeding $-12 \mathrm{~dB}$ and $Z_{\mathrm{h}}$ lower than $35 \mathrm{~dB} Z_{\mathrm{h}}$ is generally associated with nonmeteorological echoes. Hence, the degree of membership to the nonmeteorological target class is chosen to be 1 for $\mathrm{DR} \geq-12 \mathrm{~dB}$. It is set to linearly decrease to 0 for DR $=-20 \mathrm{~dB}$. A threshold for $Z_{\mathrm{h}}$ is not considered since this enables to detect strong ground echoes. Besides, the fuzzy logic does not solely depend on DR, implying that moderate to heavy rainfall is not necessarily removed. To better underpin the choice of the membership values, the distribution for each decision variable in the 4-h calibration dataset from Fig. 3 is visualized in Fig. 4, distinguishing between nonmeteorological and meteorological echoes. The distributions correspond well with the chosen membership functions.

\section{2) DETERMINING OPTIMAL WEIGHTS AND THRESHOLD}

Optimal weights are determined by employing data from one radar to limit computational time. The coastal radar in Den Helder is selected for this, because it is most vulnerable to anomalous propagation, often resulting in sea clutter. Four separate hours with data, each from a
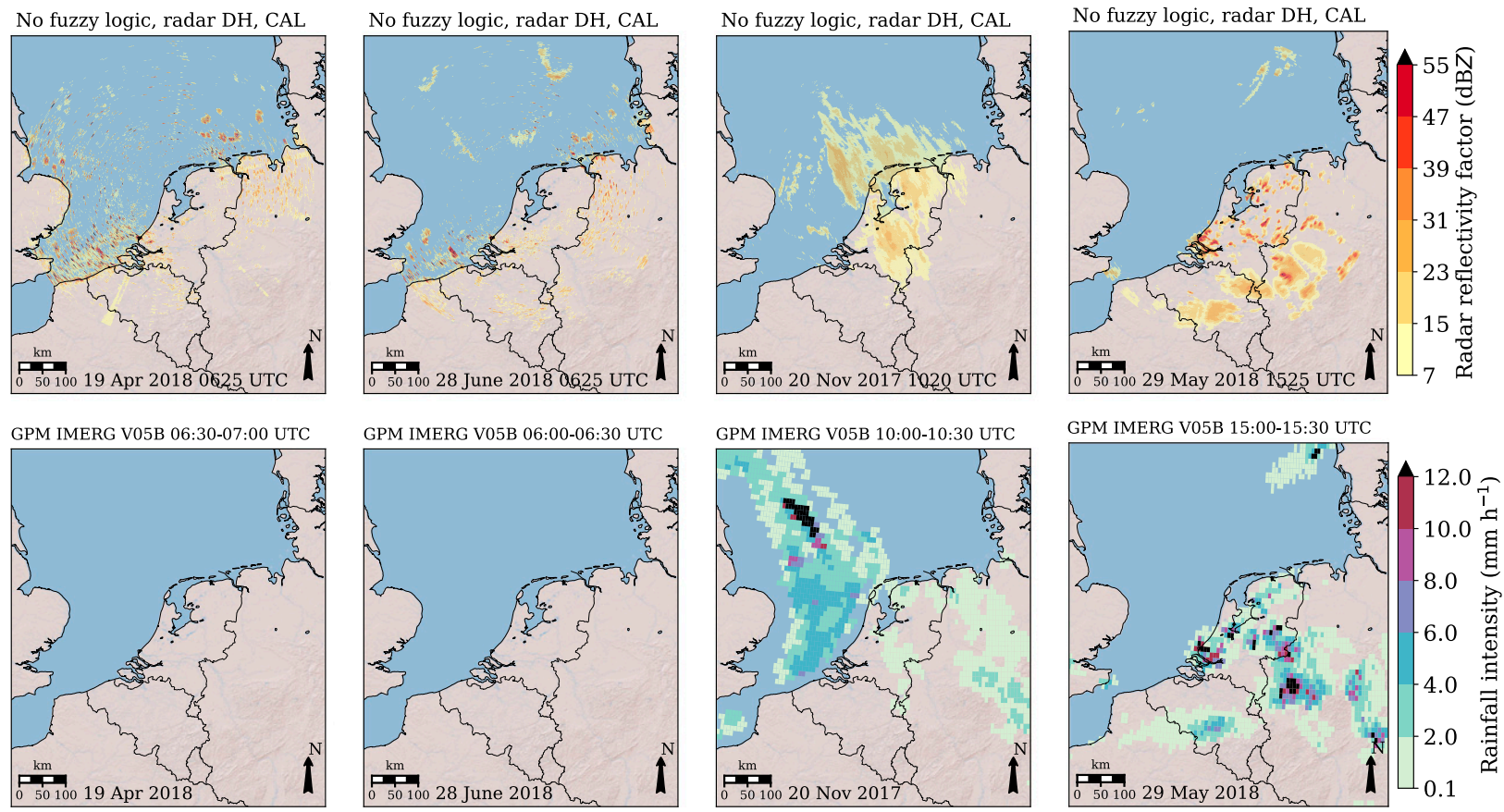

FIG. 3. Calibration dataset. (top) Maps of pseudo-CAPPI images of horizontally polarized radar reflectivity factors for the Netherlands and surroundings from the radar in Den Helder. Each map is representative of $1 \mathrm{~h}$ of the calibration dataset, with (two first columns) events with probably only nonmeteorological echoes, (third column) a stratiform rainfall event, and (fourth column) a convective rainfall event. (bottom) Corresponding rainfall intensities from GPM IMERG V05B Final Run precipitationCAL (0600-0630 UTC 19 Apr 2018 seemed to provide erroneous data, so the next $30 \mathrm{~min}$ is shown). The IMERG maps cover roughly half of the calibration period. See supplemental material file S1.gif for a movie showing the reflectivities for the four complete calibration datasets. 

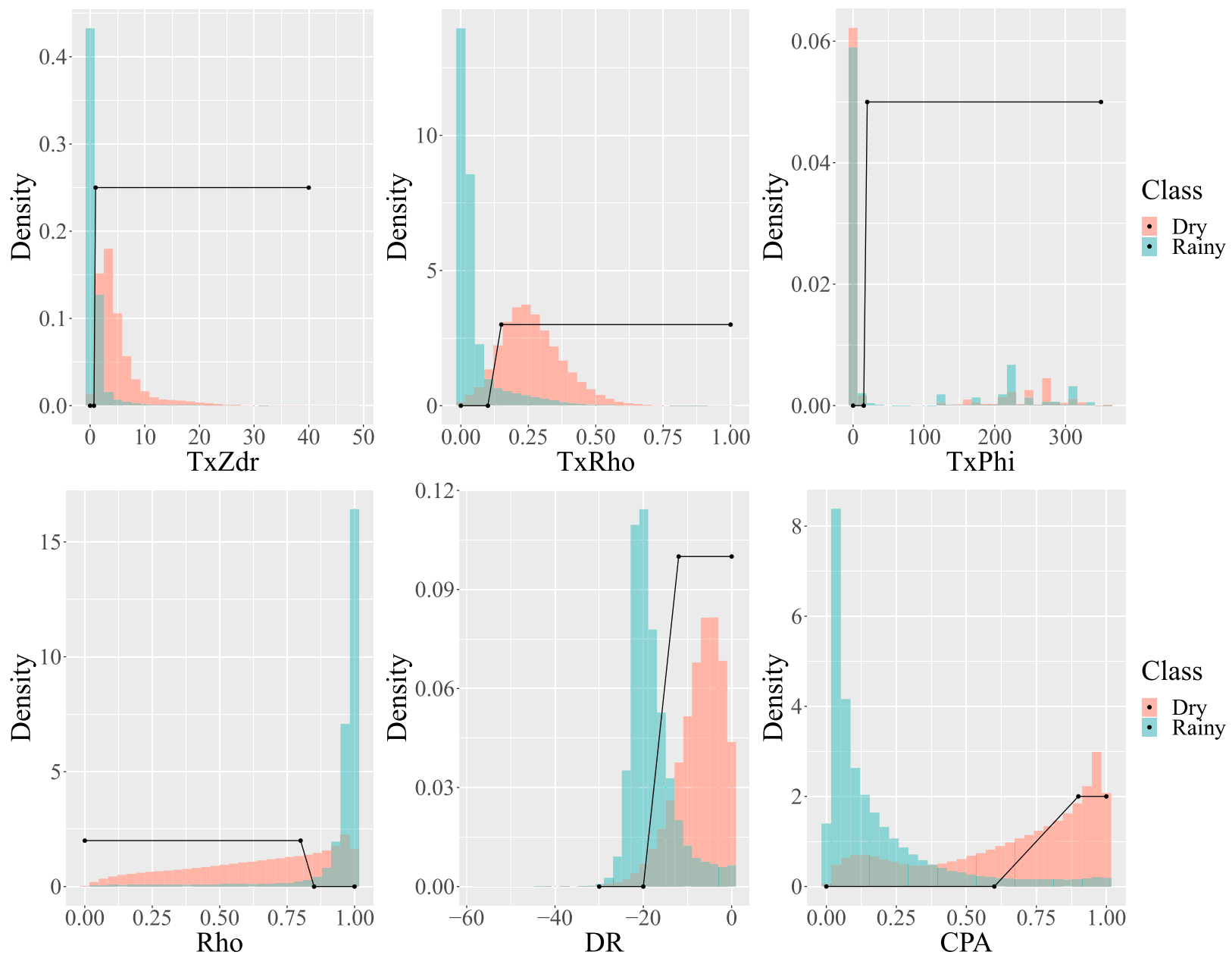

FIG. 4. The empirical distribution of the values for each decision variable in the 4-h calibration dataset, distinguishing between the 2-h nonmeteorological ("dry") and 2-h meteorological ("rainy") dataset. The black lines represent the employed membership functions.

different day, are used as a calibration dataset for determining optimal weights and threshold of the fuzzy logic algorithm. Two hours are considered dry and all echoes in these hours are labeled as nonmeteorological, whereas the other $2 \mathrm{~h}$ are assumed to only contain meteorological echoes. This is confirmed by visual inspection of the pseudoCAPPI images from the Den Helder radar in the top panels of Fig. 3, showing maps of $Z_{\mathrm{h}}$ representative for each hour, as well as the movie in online supplemental material (see $\mathrm{S} 1$. gif). For the $2 \mathrm{~h}$ assumed to only contain meteorological echoes, some nonmeteorological echoes seem to exist. These are expected to have a negligible effect on the outcome. Moreover, the dense daily rain gauge network does not reveal any significant precipitation for the land surface of the Netherlands for the $2 \mathrm{~h}$ considered as dry. The lack of significant precipitation for ungauged areas is confirmed by the IMERG rainfall maps in the bottom panels of Fig. 3.

For each decision variable the weights are varied from 0 to 0.35 with steps of 0.05 . Only combinations for which the summed weights over all variables are 1 are considered, similar to Berenguer et al. (2006). Using six decision variables this results in 15853 combinations, which are run for four different values of the threshold used to classify echoes: $0.3,0.4,0.5$, and 0.6 . The number of correctly determined nonmeteorological and meteorological echoes as well as the number of wrongly classified nonmeteorological and meteorological echoes are computed for each of the combinations and threshold values, resulting in four metrics. This is only counted for range bins with $Z_{\mathrm{h}} \geq 7 \mathrm{~dB} Z_{\mathrm{h}}$. Since this corresponds to only $0.1 \mathrm{~mm} \mathrm{~h}^{-1}$ and this thresholding is also applied in operational products, this helps to focus on echoes strong enough to be relevant for QPE. Next, the optimal values for weights and threshold are determined by selecting the highest percentage of correctly classified meteorological echoes under the condition that more than $95 \%$ of nonmeteorological echoes are detected. Table 2 shows the optimal values for the weight of each decision variable, which result in removing $95.1 \%$ of the nonmeteorological 
echoes, whereas $88.8 \%$ of the meteorological echoes are preserved in the calibration dataset. The weight of "TxPhi" is 0 implying that it does not contribute to the classification.

\section{3) IlLustration}

The application of the fuzzy logic algorithm with optimal weights and threshold is illustrated in Fig. 5 for one time interval from the lowest elevation scan from the coastal radar in Den Helder that is not part of the calibration dataset. Each of the six decision variables are displayed together with their corresponding degree of meteorological membership. The total degree of meteorological membership is shown, as well as a map with the classification result. The IMERG rainfall intensity map reveals no precipitation except for small areas in the northwest and a larger area in the southeast. The network of 321 manual rain gauges did not report significant precipitation over the land surface of the Netherlands for this day. Note that "TxPhi" has a weight of 0 , but it is nonetheless shown because it is often employed for clutter classification, and was used as a potential decision variable in our algorithm.

Three maps of $Z_{\mathrm{h}}$ are provided. The first one shows dramatic nonmeteorological echoes when Doppler filtering and fuzzy logic are discarded. The second one shows that the application of Doppler filtering effectively reduces clutter. In the third map both the Doppler filtering and the fuzzy logic algorithm are applied. The range bins with blue values in the map with the classification result are set to NA in the map of $Z_{\mathrm{h}}$. This leads to an additional strong reduction in nonmeteorological echoes. It is clear that both the Doppler filter and the fuzzy logic algorithm are important for removing clutter. The fuzzy logic algorithm is especially effective over sea, where most clutter targets are nonstationary.

\section{b. Pseudo-CAPPI per radar}

For each radar horizontal cross sections of horizontally polarized radar reflectivity at constant altitude, called pseudo-CAPPI, are constructed from the volumetric radar data. These pseudo-CAPPI images contain 8-bit reflectivity values, quantized in levels of $0.5 \mathrm{~dB} Z_{\mathrm{h}}$, at $\sim 1-\mathrm{km}$ spatial resolution. Figure 2 displays the volume coverage pattern, where the thick line denotes the pseudo-CAPPI at $1500 \mathrm{~m}$. To reduce the risk of ground clutter and beam blockage near the radar, for the first $40 \mathrm{~km}$ from the radar only data from the $2.0^{\circ}$ elevation are used. For the domain from 40 to $121 \mathrm{~km}$ from the radar, the pseudo-CAPPI is constructed by linear interpolation of the reflectivity values $\left(\mathrm{dB} Z_{\mathrm{h}}\right)$ of the nearest elevation below and above the $1500-\mathrm{m}$ height. This interpolation is done in logarithmic space, which is the default method in operational radar processing software, to further reduce the influence of nonmeteorological echoes. Only the reflectivity values of the lowest elevation are used for areas located $121 \mathrm{~km}$ and beyond from the radar. Note that the middle of the beam of the lowest elevation is at $1500 \mathrm{~m}$ for a range of $121 \mathrm{~km}$.

\section{c. Compositing pseudo-CAPPI images}

The pseudo-CAPPI images from the individual radars are combined into one composite using range-weighted compositing, where reflectivities close to the radar are assigned lower weights to limit the impact of bright bands and spurious echoes; i.e., the other radar is assigned higher weights. This compositing method prevents the occurrence of discontinuities in the radarderived rainfall images in the vicinity of the radar and at the edge of the coverage of a radar (Overeem et al. 2009). Composites are only obtained if the pseudoCAPPIs from both radars contain data, in which case the reflectivity values are linearly averaged; i.e., the arithmetic mean is computed. This linear averaging is preferential for merging, but very high outliers remain if clutter has not been sufficiently removed from the input data. The reduction would then be $3 \mathrm{~dB}$, so, e.g., $60 \mathrm{~dB} Z_{\mathrm{h}}$ for one radar and $-31 \mathrm{~dB} Z_{\mathrm{h}}$ for the other radar would lead to a still very large value of $\sim 57 \mathrm{~dB} Z_{\mathrm{h}}$ (not considering the range weighting). To hide the effect of nonmeteorological echoes, averaging is also done in logarithmic space. Thus, two datasets of composites are obtained. Warren and Protat (2019) claim that interpolation of $Z_{\mathrm{h}}$ is more accurate than that of $\mathrm{dB} Z_{\mathrm{h}}$, whereas Lakshmanan (2012) advocates the opposite.

\section{d. Rainfall retrieval}

Reflectivities below $7 \mathrm{~dB} Z_{\mathrm{h}}\left(\sim 0.1 \mathrm{~mm} \mathrm{~h}^{-1}\right)$ are not converted to rainfall intensities to avoid the accumulation of noise. Reflectivities above $55 \mathrm{~dB} Z_{\mathrm{h}}\left(\sim 100 \mathrm{~mm} \mathrm{~h}^{-1}\right)$ are set to $55 \mathrm{~dB} Z_{\mathrm{h}}$ to suppress the influence of echoes induced by hail or strong residual clutter. Isolated pixels with $Z_{\mathrm{h}} \geq$ $7 \mathrm{~dB} Z_{\mathrm{h}}$, i.e., pixels where none of the eight neighboring pixels have values $\geq 7 \mathrm{~dB} Z_{\mathrm{h}}$, are not used in the conversion to rainfall intensity. Next, the reflectivities $Z_{\mathrm{h}}\left(\mathrm{mm}^{6} \mathrm{~m}^{-3}\right)$ of the pseudo-CAPPI images are converted to rainfall intensities $R\left(\mathrm{~mm} \mathrm{~h}^{-1}\right)$ with the fixed $Z_{\mathrm{h}}-R$ relationship (Marshall et al. 1955), independent of season or type of rain,

$$
Z_{\mathrm{h}}=200 R^{1.6}
$$

implicitly assuming an exponential drop size distribution, Rayleigh scattering and a power law for the terminal fall speed of drops as a function of diameter. With $0.5-\mathrm{dB} Z_{\mathrm{h}}$ classes this results in 97 possible levels of rainfall intensities ranging from 0.1 to $100 \mathrm{~mm} \mathrm{~h}^{-1}$. One-hour rainfall accumulations are constructed from the 5-min rainfall intensities if at least 10 images (minimum availability of 

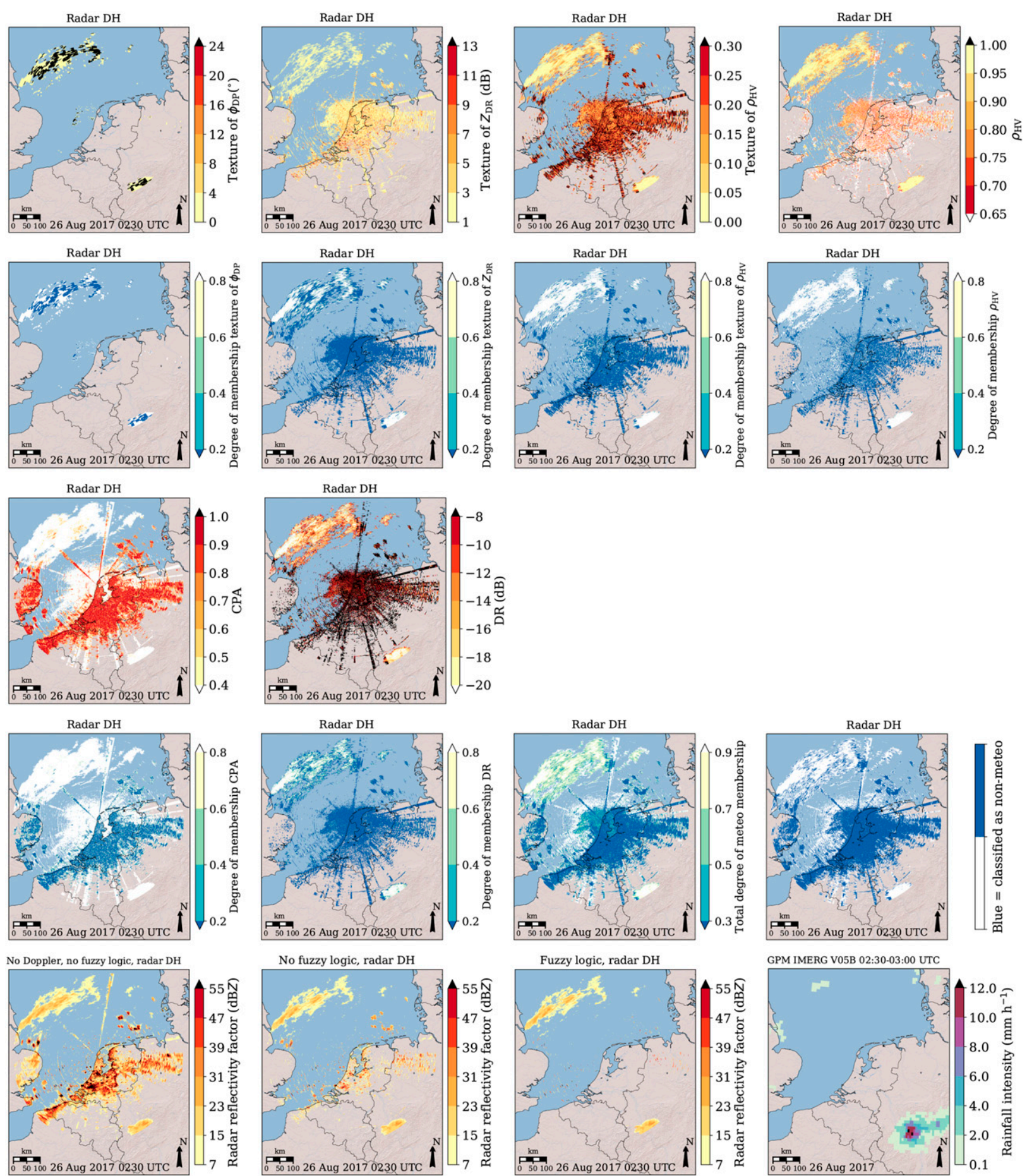

FIG. 5. Maps of the Netherlands and surroundings dominated by nonmeteorological echoes, showing (first row),(third row) values of the fuzzy logic decision variables, (second row),(fourth row) their associated degree of membership of meteorological echoes, and (fifth row) radar reflectivity factors $\left(Z_{\mathrm{h}}\right)$ and the rainfall intensities from GPM IMERG V05B Final Run precipitationCAL, for 0230 UTC 26 Aug 2017 from the validation dataset. Data are from the $0.3^{\circ}$-elevation scan from the coastal radar in Den Helder. The fourth row also shows the classification result from the fuzzy logic algorithm and the fifth row the resulting filtered $Z_{\mathrm{h}}$. See supplemental material file S2.gif for a zoomed-in movie of a 2.5 -h period including this time interval, but based on the pseudo-CAPPI images from both radars, combined employing linear compositing. 


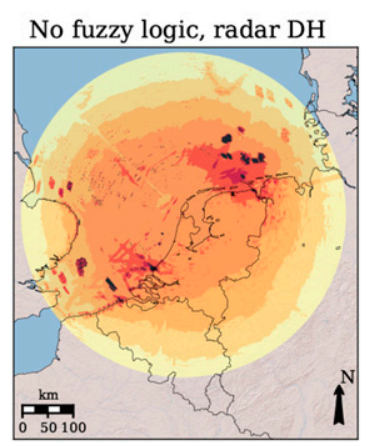

No fuzzy logic, lin. comp.

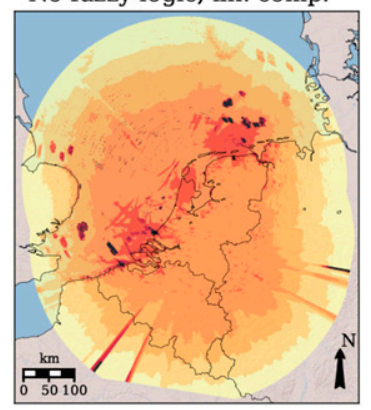

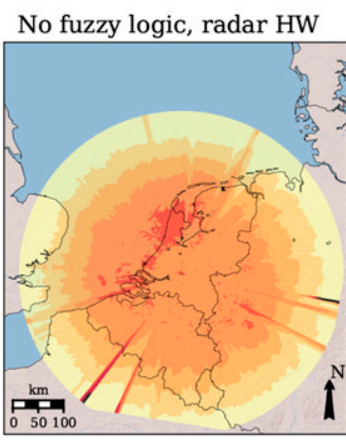

No fuzzy logic, log. comp.

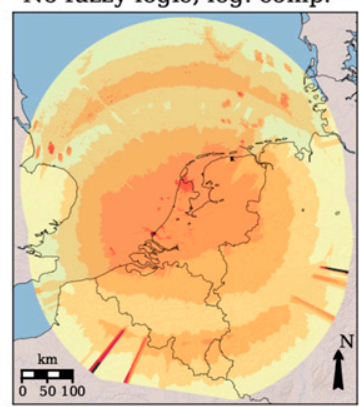

Fuzzy logic, radar DH

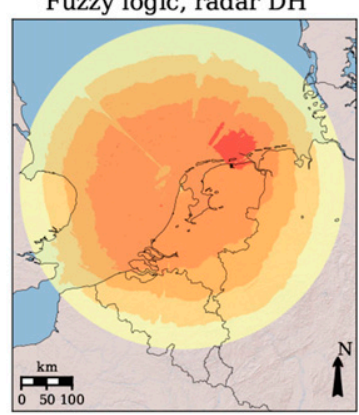

Fuzzy logic, lin. comp.

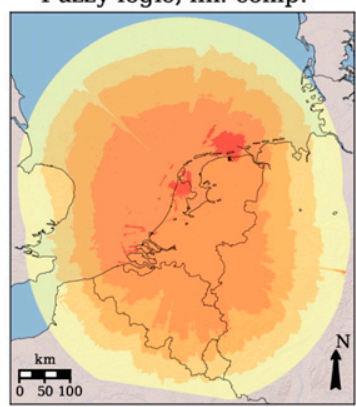

Fuzzy logic, radar HW

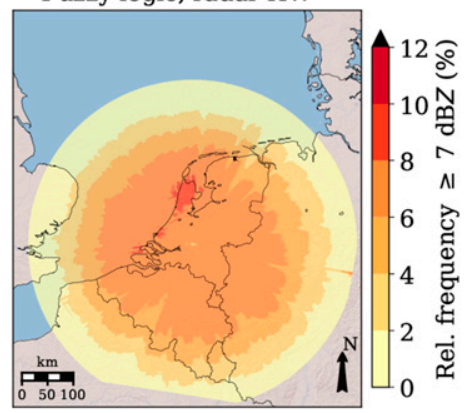

Fuzzy logic, log. comp.

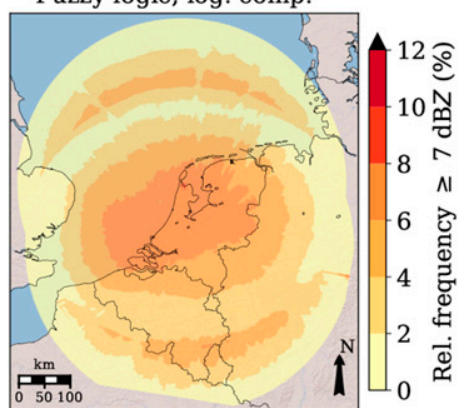

FIG. 6. Relative frequency (\%) of $\geq 7 \mathrm{~dB} Z_{\mathrm{h}}$ exceedance of radar reflectivity factors $\left(Z_{\mathrm{h}}\right)$ for the Netherlands and surroundings based on August 2017-July 2018. (top) Based on the pseudo-CAPPI images from the radar in Den Helder (DH) or Herwijnen (HW). (bottom) Composited radar images in linear space and in logarithmic space. (first column),(second column) No fuzzy logic filtering. (third column),(fourth column) Fuzzy logic filtering has been applied.

$83.3 \%$ ) are available. Local outliers caused by accumulated residual clutter are removed from the hourly accumulations using a five-pixel median filter on nearest-neighbor pixels. If one or two images are missing, the 1-h accumulated rainfall is scaled by the fraction of available images. Next, only those 1-h depths are selected for which the data availability of the corresponding 24-h (0800-0800 UTC) period is at least $83.3 \%$. These minimum availabilities are demanded to allow a fair comparison with rain gauge accumulations. The resulting data availability of the images containing hourly and daily rainfall depths is $\sim 97 \%$.

\section{Results}

Now the fuzzy logic algorithm is applied to a 1-yr dataset from elevation scans 5, 6, and 7 (see Table 1) from two radars employing the (optimal) parameter settings from Table 2. If Doppler filtering has not been applied this is explicitly stated.

\section{a. Relative frequency of exceedance of radar reflectivity factors}

The relative frequency of exceeding a threshold value for $Z_{\mathrm{h}}$, based on a full year, is visualized to spot suspicious range bins, where high values point to nonmeteorological echoes. This is done for the pseudo-CAPPI images from the radar in Den Helder (DH), the radar in Herwijnen (HW) and their composites, either averaged in linear or in logarithmic space.

Figure 6 presents the relative frequency of exceedance of $7 \mathrm{~dB} Z_{\mathrm{h}}$, i.e., the percentage to be converted to nonzero rainfall intensity. When the fuzzy logic algorithm is not applied, a lot of sea clutter is found for the Den Helder radar, whereas the Herwijnen radar notably suffers from interferences. The clutter above sea is likely induced by moving waves, ships, and wind farms. The fuzzy logic algorithm successfully removes a large part of the (sea) clutter and of the interferences. Some clutter areas become smaller due to the influence of the Herwijnen radar. In the composites, it is apparent that west of the Netherlands an increase in exceedance frequency is found for some areas, with respect to the frequencies from the individual radars. This is caused by the fact that the threshold exceedances do not always occur simultaneously for both radars. Application of the fuzzy logic algorithm leads to a strong reduction in the frequency of these suspicious echoes. It also shows that the large area with a frequency of $6 \%-$ $8 \%$ is somewhat reduced in size, which is an indication that some precipitation is removed. Still some areas likely containing sea clutter are present. Compositing in logarithmic space is very effective in hiding clutter, although interferences and some sea clutter remain present. It performs 
No fuzzy logic, radar DH

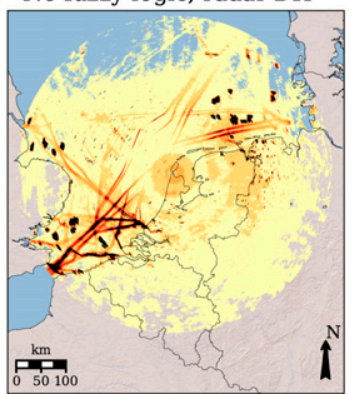

No fuzzy logic, lin. comp.

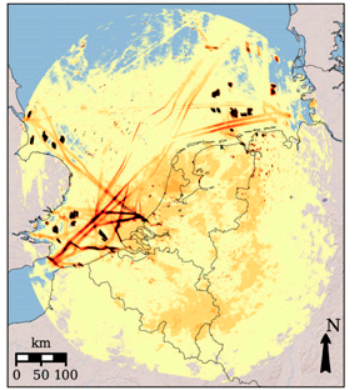

No fuzzy logic, radar HW

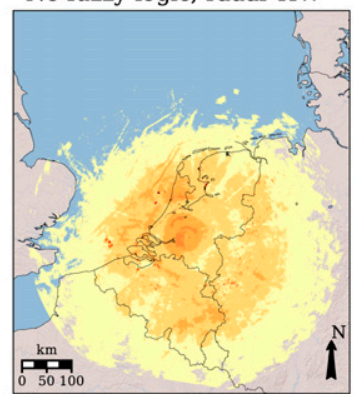

No fuzzy logic, log. comp.

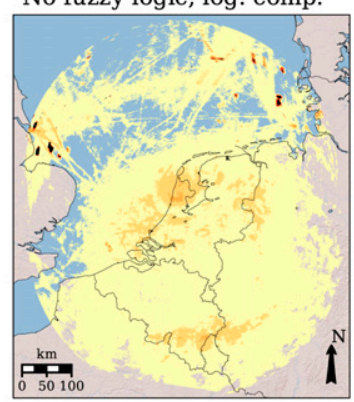

Fuzzy logic, radar DH

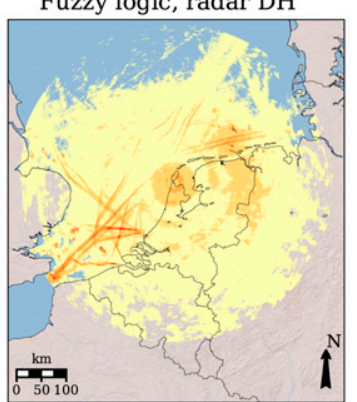

Fuzzy logic, lin. comp.

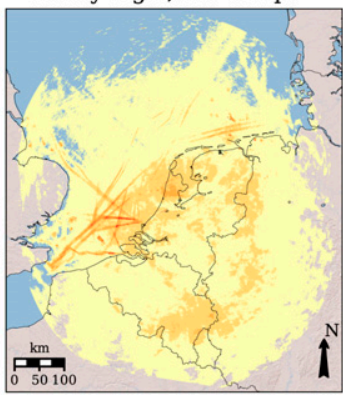

Fuzzy logic, radar HW

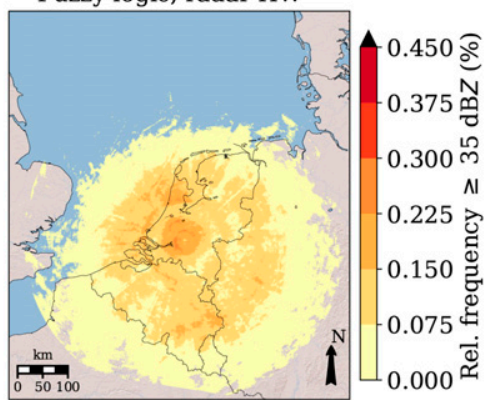

Fuzzy logic, log. comp.

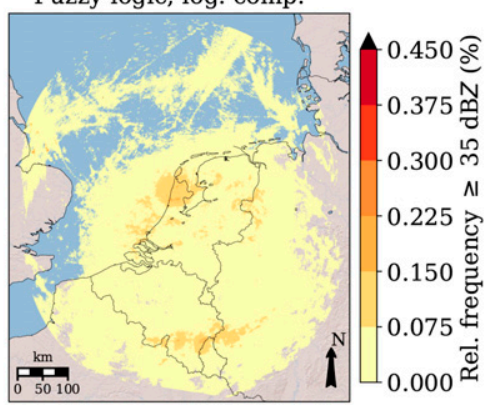

FIG. 7. Relative frequency ( $\%$ ) of $\geq 35 \mathrm{~dB} Z_{\mathrm{h}}$ exceedance of radar reflectivity factors $Z_{\mathrm{h}}$ for the Netherlands and surroundings based on August 2017-July 2018, corresponding to moderate to heavy rainfall. (top) Based on the pseudo-CAPPI images from the radar in Den Helder (DH) or Herwijnen (HW). (bottom) Composited radar images in linear space and in logarithmic space. (first column),(second column) No fuzzy logic filtering. (third column), (fourth column) Fuzzy logic filtering has been applied.

better than the linearly averaged composite in terms of presence of clutter. However, the number of exceedances of the $7 \mathrm{~dB} Z_{\mathrm{h}}$ threshold shows a more homogeneous pattern over the Netherlands for linear compositing, indicating that this may improve QPE quality over logarithmic compositing in areas without clutter. A downside of logarithmic compositing is that the overall exceedance frequency is substantially reduced, which points to rainfall underestimation. This will be investigated in the next subsection by verification with rain gauge data.

Similar results are obtained for the relative frequency of exceedance of $35 \mathrm{~dB} Z_{\mathrm{h}}$ (Fig. 7), equivalent to moderate to heavy rainfall, but with some exceptions: 1) interferences are not noticeable; 2) shipping dominates for the Den Helder radar; 3 ) the severity of clutter is less effectively reduced by the fuzzy logic algorithm, although a large reduction for shipping and wind farms is found for the Den Helder radar; and 4) application of the fuzzy logic algorithm leads to relative frequencies becoming 0 for some areas at far range from an individual radar in the northern part of the images.

\section{b. Verification of hourly and daily rainfall depths}

An independent verification of daily (0800-0800 UTC) and hourly radar rainfall depths against rain gauges is performed to quantify the influence of the fuzzy logic algorithm. Since ground echoes at the gauge locations will usually be rare, this is mainly meant to assess the unwanted removal of precipitation. In addition, the performance of logarithmic compositing is compared to linear compositing. Table 3 shows metrics for the relative bias of radar rainfall depths compared to the corresponding gauge rainfall depths, the residual standard deviation, the Pearson correlation coefficient, and the mean absolute error for daily rainfall. Here a residual is defined as the radar rainfall depth minus the gauge rainfall depth. Results are presented for all values and for those where radar and/or gauge exceed a threshold value (the radar is also included in the selection to show a possible influence of clutter). A number of conclusions can be drawn from Table 3:1) radar severely underestimates rainfall by $44.9 \%-59.9 \%$; 2) the average underestimation is $\sim 7-9$ percentage points higher for composites averaged in logarithmic space than for linearly averaged composites; 3) application of the fuzzy logic algorithm slightly increases the underestimation by $2-4$ (logarithmic averaging) or about 2-3 (linear averaging) percentage points; 4 ) the fuzzy logic algorithm generally hardly affects the values of the other metrics, except for the improvement found for the residual standard deviation and the correlation coefficient for the 10.0- and 20.0-mm threshold in case of linear averaging; and 5) higher threshold values lead to lower Pearson correlation 
TABLE 3. Validation of 24-h 0800 UTC rainfall accumulations of radar composites. Mean daily rainfall depth of the manual rain gauges, bias in the mean daily rainfall, residual standard deviation, Pearson correlation coefficient, and mean absolute error are given for the validation with the manual rain gauge network over the period August 2017-July 2018. "Threshold" means that radar and/or gauge are above the threshold value. Compositing data from both radars has been done in either logarithmic space or by linearly averaging reflectivities.

\begin{tabular}{|c|c|c|c|c|c|}
\hline Threshold (mm) & Mean (mm) & Relative bias (\%) & Std dev (mm) & Correlation & $\operatorname{MAE}(\mathrm{mm})$ \\
\hline \multicolumn{6}{|c|}{ No fuzzy logic (logarithmic space) } \\
\hline & 2.37 & -55.9 & 2.97 & 0.86 & 1.45 \\
\hline 0.1 & 4.26 & -55.9 & 3.66 & 0.83 & 2.61 \\
\hline 10.0 & 16.48 & -57.4 & 5.21 & 0.70 & 9.66 \\
\hline 20.0 & 28.25 & -52.3 & 7.37 & 0.57 & 15.14 \\
\hline \multicolumn{6}{|c|}{ Fuzzy logic (logarithmic space) } \\
\hline & 2.37 & -58.1 & 3.04 & 0.86 & 1.48 \\
\hline 0.1 & 4.32 & -58.1 & 3.75 & 0.83 & 2.70 \\
\hline 10.0 & 16.52 & -59.9 & 5.18 & 0.71 & 10.01 \\
\hline 20.0 & 28.36 & -56.1 & 6.94 & 0.59 & 16.04 \\
\hline \multicolumn{6}{|l|}{ No fuzzy logic (linear space) } \\
\hline & 2.37 & -47.6 & 2.82 & 0.85 & 1.36 \\
\hline 0.1 & 4.09 & -47.7 & 3.48 & 0.82 & 2.34 \\
\hline 10.0 & 16.31 & -50.4 & 5.78 & 0.64 & 8.82 \\
\hline 20.0 & 27.90 & -44.9 & 9.12 & 0.43 & 13.83 \\
\hline \multicolumn{6}{|l|}{ Fuzzy logic (linear space) } \\
\hline & 2.37 & -49.5 & 2.77 & 0.88 & 1.33 \\
\hline 0.1 & 4.25 & -49.6 & 3.43 & 0.85 & 2.39 \\
\hline 10.0 & 16.44 & -52.2 & 5.12 & 0.71 & 8.87 \\
\hline 20.0 & 28.18 & -47.8 & 7.30 & 0.58 & 13.96 \\
\hline
\end{tabular}

coefficients because many small or zero values are not taken into account anymore.

Table 4 has the same layout as Table 3, but shows the validation of hourly rainfall accumulations. The following conclusions can be drawn: 1) radar severely underestimates rainfall by $40.7 \%-63.8 \%$, which can be more severe compared to Table $3 ; 2$ ) the average underestimation is $\sim 7-11$ percentage points higher for composites averaged in logarithmic space with respect to those obtained by averaging in linear space; and 3) application of the fuzzy logic algorithm slightly increases the underestimation by 3-5 (logarithmic averaging) or about 3-6 (linear averaging) percentage points. Conclusions 4), now for thresholds of 5.0 and $10.0 \mathrm{~mm}$, and 5) for Table 3 (daily rainfall) also hold for Table 4 (hourly rainfall).

\section{c. Annual rainfall depths}

Annual rainfall maps are presented in Fig. 8. They show the total impact of (the removal of) nonmeteorological echoes on the variable used for many hydrometeorological applications. The fact that rainfall variability in annual rainfall maps is relatively smooth helps to detect radar pixels with unrealistically large rainfall depths due to clutter. Results are shown for composites based on logarithmic and linear averaging. The maps for which no Doppler and fuzzy logic filtering are applied show a lot of artifacts, many of which are removed when Doppler filtering is applied. For the accumulation based on linearly averaged composites huge rainfall depths are found above the North Sea. These are likely caused by maritime transport, mainly to and from the Ports of Rotterdam (the Netherlands) and Antwerp (Belgium). The application of the fuzzy logic algorithm removes many nonmeteorological echoes. An even more pronounced removal is revealed in the maps presenting the fraction of annual rainfall depth left after fuzzy logic filtering, especially for the linearly averaged composites. Despite a strong reduction, the shipping tracks are still present. The notorious clutter area known as "Maasvlakte (2)," which is part of the Port of Rotterdam and hence contains many cranes and containers giving strong backscatter in case of refraction, is effectively removed. For the compositing method in linear space, no overall reduction in annual rainfall depths is found, which demonstrates that precipitation echoes are not systematically removed by applying the fuzzy logic algorithm, consistent with the results in the previous subsection. In contrast, for the composites averaged in logarithmic space, a reduction of $5 \%-15 \%$ at long range from the radars is found when the fuzzy logic algorithm is applied. Given the good performance and the fact that only little 
TABLE 4. Validation of 1-h (clock hour) rainfall accumulations of radar composites. Mean hourly rainfall depth of the automatic rain gauges, bias in the mean hourly rainfall, residual standard deviation, Pearson correlation coefficient, and mean absolute error are given for the validation with the automatic rain gauge network over the period August 2017-July 2018. "Threshold" means that radar and/or gauge are above the threshold value. Compositing data from both radars has been done in either logarithmic space or by linearly averaging reflectivities.

\begin{tabular}{|c|c|c|c|c|c|}
\hline Threshold (mm) & Mean (mm) & Relative bias (\%) & Std dev (mm) & Correlation & $\operatorname{MAE}(\mathrm{mm})$ \\
\hline \multicolumn{6}{|c|}{ No fuzzy logic (logarithmic space) } \\
\hline & 0.09 & -51.3 & 0.33 & 0.81 & 0.06 \\
\hline 0.1 & 0.82 & -52.3 & 0.91 & 0.74 & 0.55 \\
\hline 5.0 & 8.08 & -56.9 & 3.53 & 0.53 & 4.88 \\
\hline 10.0 & 14.67 & -58.7 & 4.97 & 0.41 & 8.94 \\
\hline \multicolumn{6}{|c|}{ Fuzzy logic (logarithmic space) } \\
\hline & 0.09 & -54.1 & 0.34 & 0.80 & 0.06 \\
\hline 0.1 & 0.84 & -55.0 & 0.94 & 0.73 & 0.56 \\
\hline 5.0 & 8.12 & -61.4 & 3.64 & 0.47 & 5.16 \\
\hline 10.0 & 14.67 & -63.8 & 5.31 & 0.23 & 9.58 \\
\hline \multicolumn{6}{|l|}{ No fuzzy logic (linear space) } \\
\hline & 0.09 & -40.7 & 0.32 & 0.78 & 0.06 \\
\hline 0.1 & 0.78 & -42.1 & 0.91 & 0.71 & 0.51 \\
\hline 5.0 & 7.70 & -46.6 & 4.24 & 0.38 & 4.66 \\
\hline 10.0 & 14.50 & -51.3 & 5.88 & 0.31 & 8.43 \\
\hline \multicolumn{6}{|l|}{ Fuzzy logic (linear space) } \\
\hline & 0.09 & -45.1 & 0.31 & 0.82 & 0.06 \\
\hline 0.1 & 0.81 & -46.3 & 0.87 & 0.76 & 0.51 \\
\hline 5.0 & 8.02 & -52.5 & 3.61 & 0.51 & 4.65 \\
\hline 10.0 & 14.67 & -54.7 & 5.28 & 0.38 & 8.57 \\
\hline
\end{tabular}

precipitation is removed for the composites averaged in linear space, there is no necessity to use composites averaged in logarithmic space. Hence, in the remainder of this study only results based on compositing in linear space are presented.

The gray areas in the map showing the fraction of annual rainfall left after application of the fuzzy logic algorithm (in linear space), contain values of 1 and larger. This seems unexpected as the fuzzy logic algorithm can only remove echoes, but can be explained by the way the pseudo-CAPPI images are constructed. In the interpolation in azimuth and height, a filtered range bin is seen as an NA value and is replaced by the value from its nearest neighbor (i.e., the value from the other azimuth or height), which may have a higher value than that from the original unfiltered range bin.

Although the area over which texture is computed increases with range, and no range-dependent correction is applied, no systematic differences in annual rainfall can be found at far range from the radars for the composites averaged in linear space.

\section{d. Case studies}

Case studies of daily and hourly rainfall depths are presented regarding the effectiveness of the fuzzy logic algorithm and its unwanted precipitation removal. This is done by plotting rainfall maps based on radar data excluding and including fuzzy logic echo removal, and interpolated gauge data. Moreover, the reduction in rainfall depth $(\mathrm{mm})$ due to the fuzzy logic algorithm is visualized. First, daily rainfall maps are investigated in Fig. 9. The first row presents a successful example of clutter removal, where ground clutter is effectively removed, but sea clutter not entirely. This day includes the time intervals presented in Fig. 3 and supplemental material (see S1.gif). The other rows are rainy days having a mixture of convective and stratiform rainfall (second row), and stratiform rainfall (third row). The fuzzy logic algorithm hardly removes any rainfall. Figure 9 also reveals a large underestimation with respect to the interpolated gauge data. It is difficult to attribute this to specific sources of error, although it is likely that the vertical profile of reflectivity plays a larger role for the stratiform case and (radome) attenuation is more dominant for the more convective case. Perhaps that the values of the coefficients in the $Z_{\mathrm{h}}-R$ relationship are suboptimal.

Figure 10 presents zoomed-in hourly rainfall maps from the eastern part of the Netherlands, including part of Germany. Since few automatic gauge data are available it is not informative to display a gauge rainfall map. The difference in 60-min rainfall is generally small, but for some pixels severe underestimations exceeding 


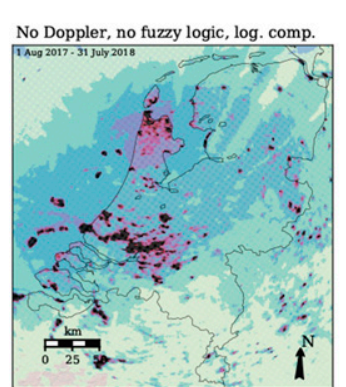

No Doppler, no fuzzy logic, lin. comp.

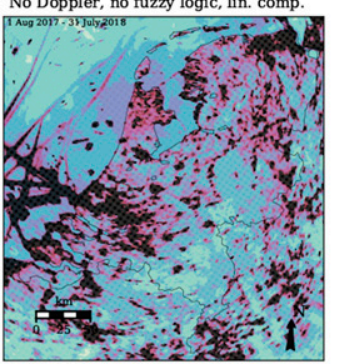

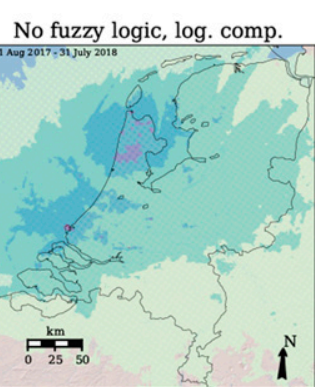

No fuzzy logic, lin. comp.

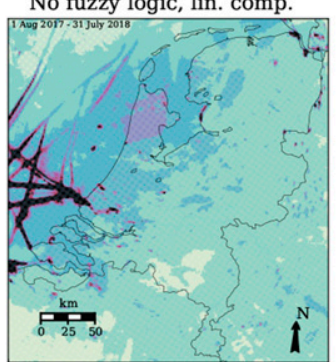

Fuzzy logic, log. comp.

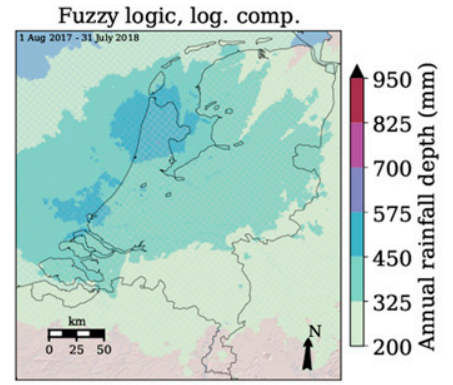

Fuzzy logic, lin. comp.

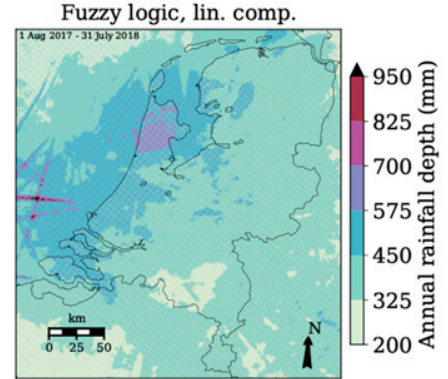

Fuzzy logic, log. comp.

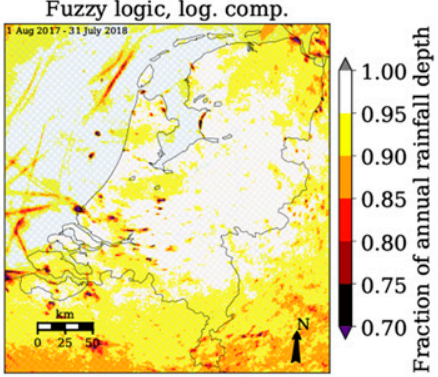

Fuzzy logic, lin. comp.

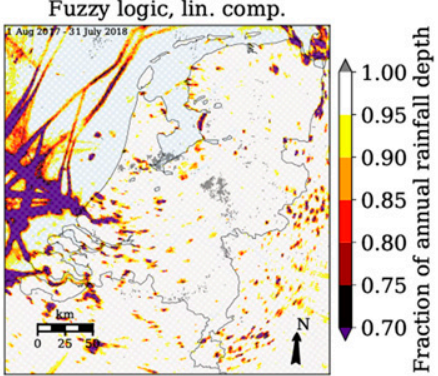

FIG. 8. Maps of annual rainfall accumulations for the Netherlands and surroundings for August 2017-July 2018 based on radar rainfall composites where data from both radars have been composited in (top) logarithmic space and (bottom) linear space. (first column) No Doppler and no fuzzy logic filtering (no clutter filtering). (second column) No fuzzy logic filtering. (third column) Fuzzy logic filtering. (fourth column) The fraction of rainfall left after applying fuzzy logic filtering.

$4 \mathrm{~mm}$, and sometimes even $12 \mathrm{~mm}$, are found. Thus, the fuzzy logic algorithm can result in much lower 60-min accumulations in convective cases for some areas. Perhaps some of these underestimations are related to the calculation of textures at the edges of convective rainfall.

\section{Discussion}

\section{a. Determining optimal weights and threshold}

Only optimal weights and threshold of the fuzzy logic algorithm are determined, whereas the shape and the values of the membership function are not. Ideally for these also optimal values should be determined, although this will be computationally (too) expensive. The condition that more than $95 \%$ of nonmeteorological echoes need to be detected in the calibration dataset could be modified depending on the specific application of the weather radar products. The chosen percentage assures that the vast majority of nonmeteorological echoes is removed, at the expense of a higher risk of removing meteorological echoes.

It is difficult to provide an exact comparison for the values of the weights with other studies, since different sets of decision variables are utilized. Moreover, climate, types of radar and computation of textures may vary as well. Crisologo et al. (2014) find similar weights for "TxRho" $(\sim 21 \%)$ and "TxPhi" $(\sim 5 \%)$ for a tropical climate. Vulpiani et al. (2012) find a similar weight for "TxRho" (20\%), but a larger weight for "TxPhi"
$(20 \%)$ in mountainous areas in Italy. Both studies use a previous version of the wradlib fuzzy logic algorithm. Krause (2016) finds a smaller weight for "TxRho" $(\sim 13 \%)$ and a much larger weight for "TxPhi" (25\%).

The 10 highest ranked optimal values for weights can be quite different. The eight ranked optimal values for weights and threshold (now 0.4 instead of 0.6 ) show the largest difference with respect to the highest-ranked ones, i.e., 0.6 when their absolute differences are summed. Part of the analyses were also performed employing these eight ranked weights and threshold to assess whether different values make a large difference (not shown). The eighth ranked values are chosen by selecting the eighthhighest percentage of correctly classified meteorological echoes under the condition that more than $95 \%$ of nonmeteorological echoes are detected. This results in removing $95.4 \%$ (compared to $95.1 \%$ for the highest ranked) of the nonmeteorological echoes, whereas $88.6 \%$ (compared to $88.8 \%$ for the highest ranked) of the meteorological echoes are preserved in the calibration dataset. Differences in the relative frequency of exceedance of $7 \mathrm{~dB} Z_{\mathrm{h}}$ for the composites, as well as in the annual rainfall depths, are small, irrespective of compositing being done in logarithmic or linear space. With the eight ranked values more shipping tracks are removed, but more isolated echoes remain, likely related to wind farms. This suggests that rather different weights can give a similar outcome, which suggests equifinality and gives 
Manual gauges, interpolated

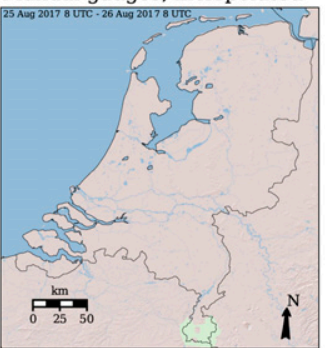

Manual gauges, interpolated

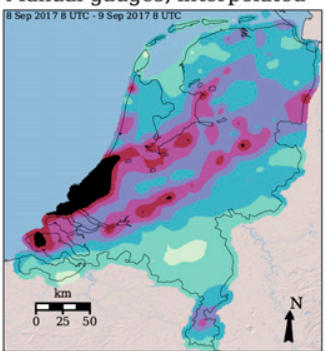

Manual gauges, interpolated

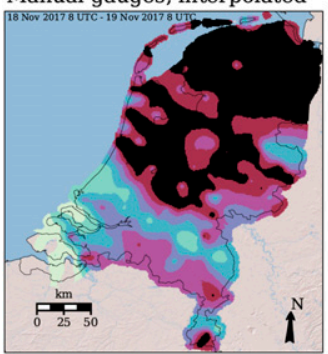

No fuzzy logic, lin. comp.

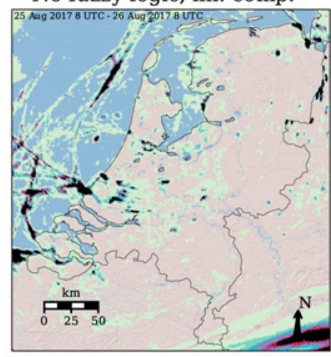

No fuzzy logic, lin. comp.

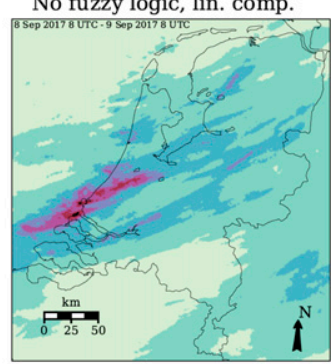

No fuzzy logic, lin. comp.

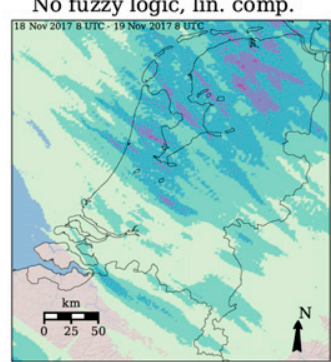

Fuzzy logic, lin. comp.

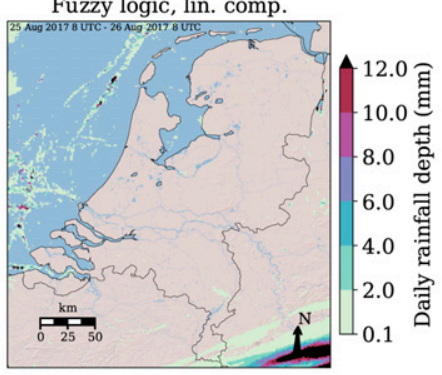

Fuzzy logic, lin. comp.

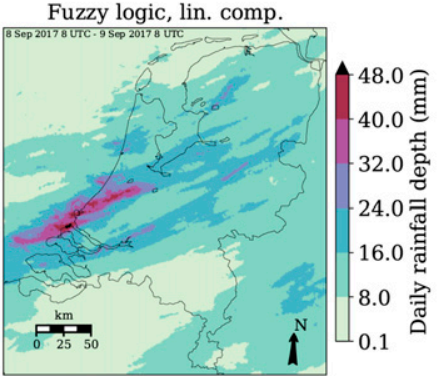

Fuzzy logic, lin. comp.

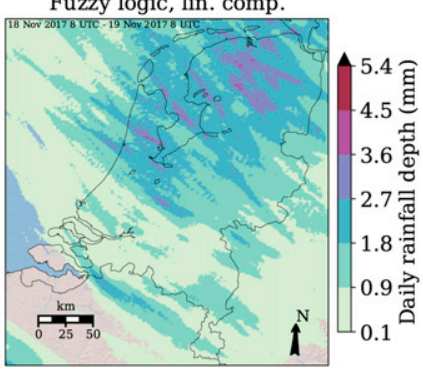

Fuzzy logic, lin. comp.

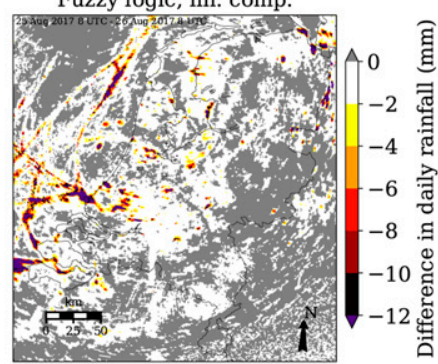

Fuzzy logic, lin. comp.

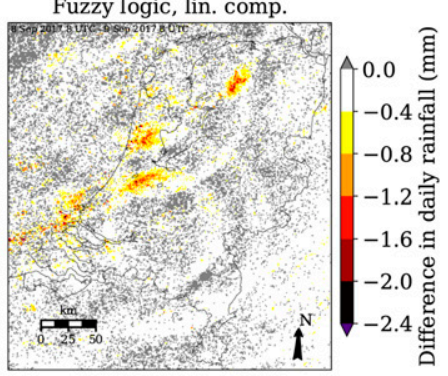

Fuzzy logic, lin. comp

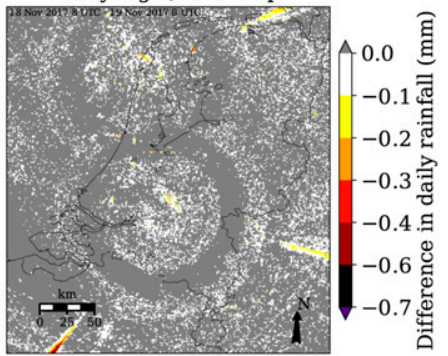

FIG. 9. Maps of daily rainfall accumulations for the Netherlands and surroundings for a day (top) dominated by nonmeteorological echoes, (middle) with a mixture of stratiform and convective rainfall, and (bottom) with stratiform rainfall. Based on (first column) interpolated data from 321 manual rain gauges, (second column) radar rainfall composites without and (third column) with fuzzy logic filtering. (fourth column) The difference in rainfall depth of fuzzy logic with respect to no fuzzy logic filtering. Data from both radars have been composited in linear space.

some confirmation of the robustness of the procedure to find optimal values. With respect to the calibration dataset, many weight and threshold combinations will give similar results as the highest ranked optimal values, since 6699 out of 63412 combinations exceed the $95 \%$ threshold for nonmeteorological echo removal. The added decision variables CPA and DR have a large and similar weight in the fuzzy logic algorithm of 0.20 . The variability in the weight values, e.g., the weight for CPA changes to 0.05 and the weight for DR changes to 0.30 for the eight ranked weights and threshold, puts the importance of CPA and DR into perspective. Although it is shown that CPA and DR can be important in a fuzzy logic algorithm, it could well be that many other combinations of weights for the decision variables, where CPA and DR play a less dominant or negligible role, would provide only slightly worse results.

To study the importance of DR and CPA in the fuzzy logic algorithm, the whole optimization procedure and application of the algorithm to a 1-yr dataset was also performed without these two decision variables (results not shown). This removes the effects of sea clutter more effectively in annual rainfall accumulations. The performance in terms of the relative frequency of exceedance of $7 \mathrm{dBZ}_{\mathrm{h}}$ is also better, although more interferences can be seen. An important shortcoming is that the relative frequency of exceedance of $35 \mathrm{~dB} Z_{\mathrm{h}}$ shows a general decrease, indicating that too many moderate to heavy rainfall echoes are removed when DR and CPA are not used. Such a reduction is also apparent in the annual rainfall accumulations.

\section{b. Compositing}

Compositing in logarithmic space effectively hides nonmeteorological echoes, but negatively affects the overall quality of precipitation estimates compared to linear compositing, daily rainfall depths being $\sim 7-8$ percentage points lower on average. One could object 
No fuzzy logic, lin. comp.

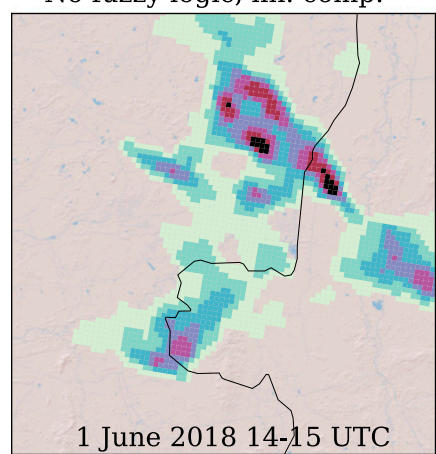

Fuzzy logic, lin. comp.

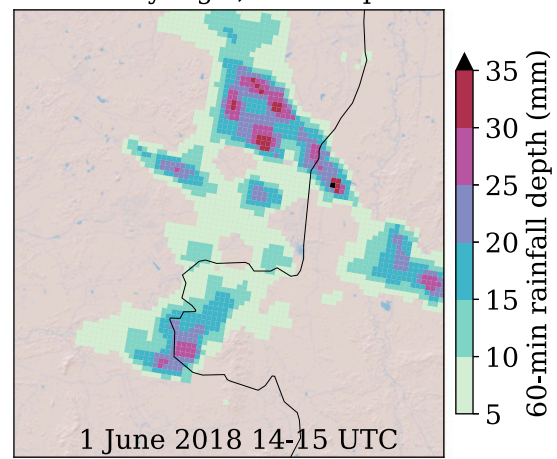

Fuzzy logic, lin. comp.

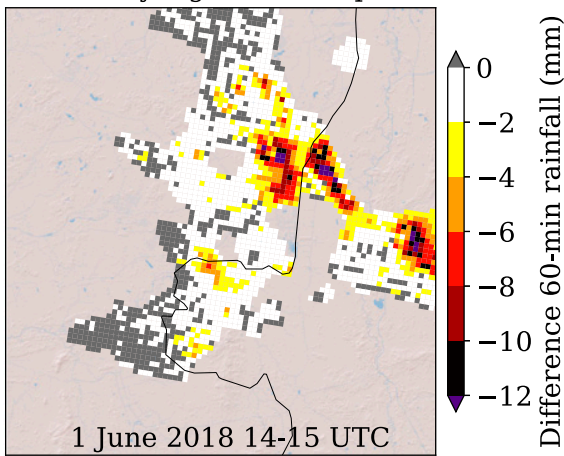

FIG. 10. Zoomed-in maps of hourly rainfall accumulations for radar rainfall composites (left) without and (center) with fuzzy logic filtering. (right) The difference in rainfall depth of fuzzy logic with respect to no fuzzy logic filtering. Data from both radars have been composited in linear space. The black line represents the border between the Netherlands and Germany.

that compositing in logarithmic space seems not to make sense from a physical viewpoint, and thus linear compositing is desirable. The fact that construction of pseudo-CAPPI images is always done in logarithmic space, however, puts this discussion in perspective. Because the fuzzy logic algorithm removes most clutter, compositing in linear space is preferred.

\section{c. Five-point median clutter filter}

Finally, Fig. 11 shows a comparison of the annual rainfall map without and with application of the fivepoint median clutter filter. This filter leads to a clear reduction in sea clutter, which is why it has been employed in all results. The statistics from Tables 3 and 4 for fuzzy logic are also computed for the dataset without median clutter filter (not shown). The values are similar for the hourly and daily rainfall where composites have been averaged in logarithmic space, although the underestimation is about $0-1.5$ percentage points less when no median clutter filter is applied. For the composites averaged in linear space small differences are sometimes found, e.g., always about $1-5$ percentage points less underestimation when no median clutter filter is applied. Taking the median value tends to only slightly reduce the radar rainfall depths on average as well as the effective spatial resolution, whereas it leads to an additional reduction in sea clutter.

\section{Conclusions}

The effectiveness of the open-source wradlib fuzzy echo classification was tested on a 1-yr dataset from two C-band weather radars in a temperate climate. The chosen settings, including the optimal weights and threshold from a 4-h calibration dataset, successfully removed many nonmeteorological echoes while removing
Manual gauges, interpolated

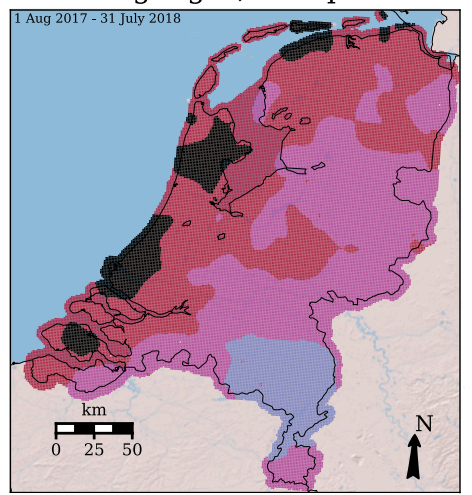

Fuzzy logic, no median, lin. comp.

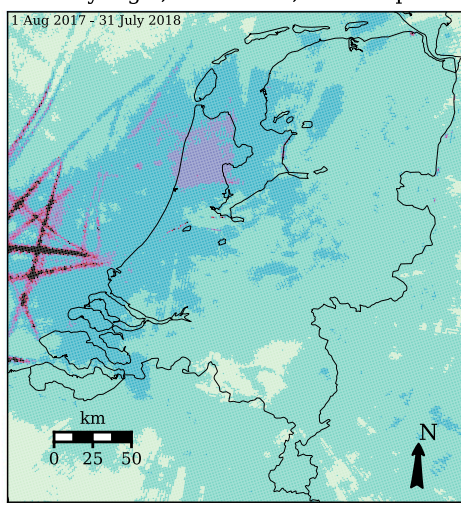

Fuzzy logic, lin. comp.

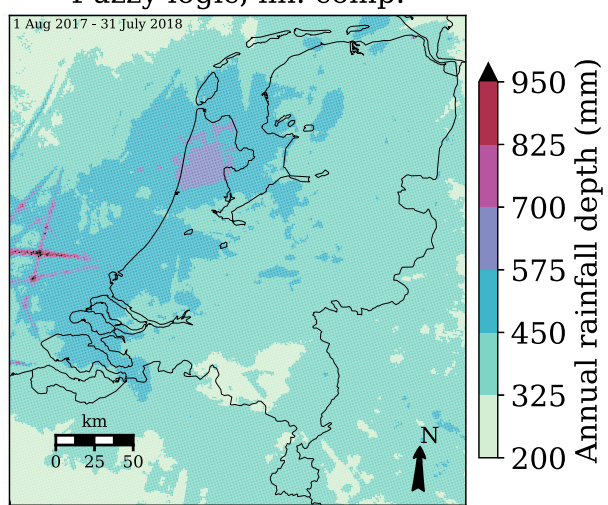

FIG. 11. Maps of annual rainfall accumulations for the Netherlands and surroundings for August 2017-July 2018 based on (left) interpolated data from 322 manual rain gauges, and (center),(right) radar rainfall composites where data from both radars have been composited in linear space and fuzzy logic filtering has been applied. The five-point median clutter filter has not been applied in the center panel. 
a little precipitation. This was confirmed by maps of exceedances of radar reflectivity factors for given thresholds, accumulated annual rainfall maps, case studies with hourly or daily rainfall maps, and an extensive verification of hourly and daily rainfall depths against rain gauges. Because the fuzzy logic algorithm removes many nonmeteorological echoes, the current practice in the Netherlands to composite data from both radars in logarithmic space to hide these echoes is abandoned and replaced by linearly averaging reflectivities. This research has led to extension of the wradlib fuzzy logic algorithm with two new variables: Clutter phase alignment (CPA) and depolarization ratio (DR), which plays a large role in the presented fuzzy logic algorithm. Despite limitations concerning the length of the calibration period, the systematic evaluation over a full year gives confidence that the proposed method and, hence, the wradlib fuzzy logic algorithm, would work well in an operational setting.

We conclude with some recommendations. Application to long, e.g., 1-yr, datasets is valuable to determine the robustness of algorithms and their chosen settings. The rise of cloud computing could bring the full-scale optimization of, e.g., fuzzy logic algorithms on long datasets to our fingertips. Often calibration datasets are on the order of hours or days, such as $4 \mathrm{~h}$ in this study, and their short length can make them less representative for a full year. Hence, much longer calibration datasets could be used to find optimal values. A drawback of this approach is that classification of echoes in calibration datasets can be laborious, especially when considering images containing both nonmeteorological and meteorological echoes. Another approach could be to just apply many different plausible combinations of weights or other plausible parameter settings to a 1-yr dataset. Next, the extensive approach presented in this study could be followed, which involves a verification against rain gauges, to verify whether sufficient nonmeteorological echoes are removed while keeping most precipitation. If good results can be established on such large datasets, it is likely to work on other datasets from a similar radar and climate. Hence, there is no need for an independent verification on a separate dataset for such a big data approach.

Remaining sea clutter shows the need for further improvement of clutter removal algorithms or testing of other algorithms on the dataset from this study. A possible way forward is quality-based compositing in linear space, where suspicious range bins get a lower weight, e.g., based on the value of the membership of the nonmeteorological target class. The latter implies that for range bins classified as meteorological a probability that they are actually nonmeteorological is taken into account. Another option is to apply other weights and threshold values for the fuzzy logic algorithm for known locations of wind farms, although this may result in discontinuities in the rainfall image. Finally, different nonmeteorological echo classes could be distinguished, each of them with their own settings (Dufton and Collier 2015; Park et al. 2009).

Finally, Fig. 11 shows that the radars strongly underestimate rainfall with respect to interpolated rain gauge data for the Netherlands, which is not caused by the clutter removal algorithm. Follow-up studies will address this by improving QPE through application of vertical profile of reflectivity correction algorithms (Hazenberg et al. 2013) or through polarimetry, e.g., by attenuation correction via specific differential phase.

Acknowledgments. We gratefully acknowledge funding from the Ministry of Infrastructure and Water Management for the project "Utilization of dual polarization capabilities of the new KNMI radars" (UDPOL-KNMI). The data employed in this study are freely available. The volumetric radar data can be retrieved from the KNMI Data Centre (https://dataplatform.knmi.nl/catalog/datasets/index. html? $\mathrm{x}$-dataset=radar_tar_volume_denhelder\&x-datasetversion $=1.0$ and https://dataplatform.knmi.nl/catalog/ datasets/index.html? $x$-dataset $=$ radar_tar_vol_full_ herwijnen \&x-dataset-version $=1.0$ ), as well as the interpolated manual rain gauge data (https://dataplatform. $\mathrm{knmi} . \mathrm{nl} / \mathrm{catalog} /$ datasets/index.html? $\mathrm{x}$-dataset=Rd1\&xdataset-version $=5$ ). The automatic and manual rain gauge data are also provided by KNMI (http://projects. knmi.nl/klimatologie/uurgegevens/selectie.cgi and https:// www.knmi.nl/nederland-nu/klimatologie/monv/reeksen; websites are in Dutch). We thank Kai Mühlbauer for adding the depolarization ratio and the clutter phase alignment to wradlib's fuzzy echo classification, as well as the computation of the depolarization ratio. We thank two anonymous reviewers for their constructive comments.

\section{REFERENCES}

Bechini, R., and V. Chandrasekar, 2015: A semisupervised robust hydrometeor classification method for dual-polarization radar applications. J. Atmos. Oceanic Technol., 32, 22-47, https:// doi.org/10.1175/JTECH-D-14-00097.1.

Beekhuis, H., and T. Mathijssen, 2018: From pulse to product, highlights of the upgrade project of the Dutch national weather radar network. 10th European Conf. on Radar in Meteorology and Hydrology, Wageningen, Netherlands, Wageningen University and Research, 960-965, https://doi.org/10.18174/454537.

Berenguer, M., D. Sempere-Torres, C. Corral, and R. SánchezDiezma, 2006: A fuzzy logic technique for identifying nonprecipitating echoes in radar scans. J. Atmos. Oceanic Technol., 23, 1157-1180, https://doi.org/10.1175/JTECH1914.1.

Crisologo, I., G. Vulpiani, C. C. Abon, C. P. C. David, A. Bronstert, and M. Heistermann, 2014: Polarimetric rainfall retrieval from a C-band weather radar in a tropical environment (the Philippines). 
Asia-Pac. J. Atmos. Sci., 50, 43-55, https://doi.org/10.1007/ s13143-014-0049-y.

Dufton, D. R. L., and C. G. Collier, 2015: Fuzzy logic filtering of radar reflectivity to remove non-meteorological echoes using dual polarization radar moments. Atmos. Meas. Tech., 8, 3985-4000, https://doi.org/10.5194/amt-8-3985-2015.

Fabry, F., 2015: Radar Meteorology: Principles and Practice. Cambridge University Press, 256 pp., https://doi.org/10.1017/ CBO9781107707405.

Gourley, J. J., P. Tabary, and J. Parent du Chatelet, 2007: A fuzzy logic algorithm for the separation of precipitating from nonprecipitating echoes using polarimetric radar observations. J. Atmos. Oceanic Technol., 24, 1439-1451, https://doi.org/ 10.1175/JTECH2035.1.

Hazenberg, P., P. J. J. F. Torfs, H. Leijnse, G. Delrieu, and R. Uijlenhoet, 2013: Identification and uncertainty estimation of vertical reflectivity profiles using a Lagrangian approach to support quantitative precipitation measurements by weather radar. J. Geophys. Res. Atmos., 118, $10243-10261$, https:// doi.org/10.1002/JGRD.50726.

Heistermann, M., S. Jacobi, and T. Pfaff, 2013: Technical note: An open source library for processing weather radar data (wradlib). Hydrol. Earth Syst. Sci., 17, 863-871, https://doi.org/ 10.5194/hess-17-863-2013.

Hou, A. Y., and Coauthors, 2014: The Global Precipitation Measurement mission. Bull. Amer. Meteor. Soc., 95, 701-722, https://doi.org/10.1175/BAMS-D-13-00164.1.

Hubbert, J. C., M. Dixon, S. M. Ellis, and G. Meymaris, 2009a: Weather radar ground clutter. Part I: Identification, modeling, and simulation. J. Atmos. Oceanic Technol., 26, 1165-1180, https://doi.org/10.1175/2009JTECHA1159.1.

$\longrightarrow,-$, and $-2009 \mathrm{~b}$ : Weather radar ground clutter. Part II: Real-time identification and filtering. J. Atmos. Oceanic Technol., 26, 1181-1197, https://doi.org/10.1175/2009JTECHA1160.1.

Kilambi, A., F. Fabry, and V. Meunier, 2018: A simple and effective method for separating meteorological from nonmeteorological targets using dual-polarization data. J. Atmos. Oceanic Technol., 35, 1415-1424, https://doi.org/10.1175/JTECH-D-17-0175.1.

KNMI, 2000: Handbook for the Meteorological Observation. KNMI, 110 pp., http://projects.knmi.nl/hawa/pdf/Handbook_ H01_H06.pdf.

Kok, C. J., B. G. J. W. Schreur, and D. H. P. Vogelezang, 2011: Meteorological support for anticipatory water management. Atmos. Res., 100, 285-295, https://doi.org/10.1016/j.atmosres.2010.08.013.

Krause, J. M., 2016: A simple algorithm to discriminate between meteorological and nonmeteorological radar echoes. J. Atmos. Oceanic Technol., 33, 1875-1885, https://doi.org/10.1175/ JTECH-D-15-0239.1.

Kumjian, M., 2013: Principles and applications of dual-polarization weather radar. Part I: Description of the polarimetric radar variables. J. Oper. Meteor., 1, 226-242, https://doi.org/10.15191/ nwajom.2013.0119.

Lakshmanan, V., 2012: Image processing of weather radar reflectivity data: Should it be done in $Z$ or dBZ? Electron.
J. Severe Storms Meteor., 7 (3), https://ejssm.org/ojs/index.php/ ejssm/article/viewArticle/102.

Leijnse, H., H. Beekhuis, and I. Holleman, 2016: Doppler clutter removal on KNMI weather radars. KNMI Tech. Rep. TR-355, $40 \mathrm{pp}$., https://bibliotheek.knmi.nl/knmipubTR/TR355.pdf.

Magaldi, A. V., J. Bech, and J. Lorente, 2009: A multisource scheme based on NWP and MSG data to correct nonprecipitating weather radar echoes. Meteor. Atmos. Phys., 105, 121-132, https://doi.org/10.1007/s00703-009-0043-6.

Marshall, J. S., W. Hitschfeld, and K. L. S. Gunn, 1955: Advances in radar weather. Advances in Geophysics, H. E. Lansberg, Ed., Vol. 2, Academic Press, 1-56.

Michelson, D. B., and D. Sunhede, 2004: Spurious weather radar echo identification and removal using multisource temperature information. Meteor. Appl., 11, 1-14, https://doi.org/ $10.1017 / \mathrm{S} 1350482703001129$.

Mühlbauer, K., and M. Heistermann, 2019: wradlib/wradlib: wradlib release 1.4.2. Zenodo, https://doi.org/10.5281/zenodo.3245745.

Overeem, A., I. Holleman, and A. Buishand, 2009: Derivation of a 10-year radar-based climatology of rainfall. J. Appl. Meteor. Climatol., 48, 1448-1463, https://doi.org/10.1175/2009JAMC1954.1.

Park, H. S., A. V. Ryzhkov, D. S. Zrnić, and K.-E. Kim, 2009: The hydrometeor classification algorithm for the polarimetric WSR-88D: Description and application to an MCS. Wea. Forecasting, 24, 730-748, https://doi.org/10.1175/ 2008WAF2222205.1.

Rauber, R. M., and S. L. Nesbitt, 2018: Radar Meteorology: A First Course. John Wiley and Sons, 488 pp., https://doi.org/10.1002/ 9781118432662.

Ryzhkov, A., and Coauthors, 2017: Estimation of depolarization ratio using weather radars with simultaneous transmission/ reception. J. Appl. Meteor. Climatol., 56, 1797-1816, https:// doi.org/10.1175/JAMC-D-16-0098.1.

Skofronick-Jackson, G., D. Kirschbaum, W. Petersen, G. Huffman, C. Kidd, E. Stocker, and R. Kakar, 2018: The Global Precipitation Measurement (GPM) mission's scientific achievements and societal contributions: Reviewing four years of advanced rain and snow observations. Quart. J. Roy. Meteor. Soc., 144, 27-48, https:// doi.org/10.1002/qj.3313.

Vivekanandan, J., D. S. Zrnić, S. M. Ellis, R. Oye, A. V. Ryzhkov, and J. Straka, 1999: Cloud microphysics retrieval using S-band dual-polarization radar measurements. Bull. Amer. Meteor. Soc., 80, 381-388, https://doi.org/10.1175/1520-0477(1999) $080<0381$ :CMRUSB $>2.0$. CO;2.

Vulpiani, G., M. Montopoli, L. D. Passeri, A. G. Gioia, P. Giordano, and F. S. Marzano, 2012: On the use of dual-polarized C-band radar for operational rainfall retrieval in mountainous areas. J. Appl. Meteor. Climatol., 51, 405-425, https://doi.org/10.1175/ JAMC-D-10-05024.1.

Warren, R. A., and A. Protat, 2019: Should interpolation of radar reflectivity be performed in $Z$ or dBZ? J. Atmos. Oceanic Technol., 36, 1143-1156, https://doi.org/10.1175/JTECH-D18-0183.1.

Zhang, G., 2017: Weather Radar Polarimetry. CRC Press, 304 pp. 